\title{
A Physiologically-Based Pharmacokinetic Model to Describe Ciprofloxacin Pharmacokinetics Over the Entire Span of Life
}

\author{
Jan-Frederik Schlender ${ }^{1,2} \cdot$ Donato Teutonico $^{2,5} \cdot$ Katrin Coboeken $^{2}$ • \\ Katrin Schnizler $^{2}$ - Thomas Eissing ${ }^{2} \cdot$ Stefan Willmann $^{3} \cdot$ Ulrich Jaehde $^{1}$. \\ Heino Stass ${ }^{4}$
}

Published online: 8 May 2018

(C) The Author(s) 2018

\begin{abstract}
Background Physiologically-based pharmacokinetic (PBPK) modeling has received growing interest as a useful tool for the assessment of drug pharmacokinetics by continuous knowledge integration.

Objective The objective of this study was to build a ciprofloxacin PBPK model for intravenous and oral dosing based on a comprehensive literature review, and evaluate the predictive performance towards pediatric and geriatric patients. Methods The aim of this report was to establish confidence in simulations of the ciprofloxacin PBPK model along the development process to facilitate reliable predictions outside of the tested adult age range towards the extremes of ages. Therefore, mean data of 69 published clinical trials were identified and integrated into the model building, simulation and verification process. The predictive performance on both ends of the age scale was assessed using individual data of 258 subjects observed in own clinical trials.
\end{abstract}

Electronic supplementary material The online version of this article (https://doi.org/10.1007/s40262-018-0661-6) contains supplementary material, which is available to authorized users.

Jan-Frederik Schlender

jan.schlender@bayer.com; jan.schlender@uni-bonn.de

1 Institute of Pharmacy, Clinical Pharmacy, University of Bonn, Bonn, Germany

2 Systems Pharmacology and Medicine, Bayer AG, 51373 Leverkusen, Germany

3 Clinical Pharmacometrics, Bayer AG, Wuppertal, Germany

4 Clinical Pharmacology, Bayer AG, Wuppertal, Germany

5 Present Address: Division of Clinical Pharmacokinetics and Pharmacometrics, Institut de Recherches Internationales Servier, Suresnes, France
Results Ciprofloxacin model verification demonstrated no concentration-related bias and accurate simulations for the adult age range, with only $4.8 \%$ of the mean observed data points for intravenous administration and $12.1 \%$ for oral administration being outside the simulated twofold range. Predictions towards the extremes of ages for the area under the plasma concentration-time curve (AUC) and the maximum plasma concentration $\left(C_{\max }\right)$ over the entire span of life revealed a reliable estimation, with only two pediatric AUC observations outside the $90 \%$ prediction interval.

Conclusion Overall, this ciprofloxacin PBPK modeling approach demonstrated the predictive power of a thoroughly informed middle-out approach towards age groups of interest to potentially support the decision-making process.

\section{Key Points}

A mechanistic understanding of absorption, distribution, metabolism and elimination processes affecting the exposure of ciprofloxacin was comprehensively elucidated in a whole-body physiologically-based pharmacokinetic approach.

The model was successfully applied to predict agerelated changes in pharmacokinetics for pediatric and geriatric patients, using an age-informed physiological database.

Further pharmacokinetic assessments in other special population groups, or an evaluation of biopharmaceutical issues during formulation development, are potential application scenarios and support subsequent pharmacodynamic model extension. 


\section{Introduction}

Ciprofloxacin is an antimicrobial agent of the fluoroquinolone class that has been extensively studied since its market approval in 1987, and is widely used in the clinic because of its broad antibacterial spectrum. Since its approval, ciprofloxacin has been applied clinically in an increasing number of indications, with a variety of administration and formulation forms. However, resistance is a constant concern to the application of fluoroquinolones as one of the major treatment options against gram-negative bacteria [1]; thus, appropriate dosing is crucial and needs to be ensured for all patient populations. The pharmacokinetics of ciprofloxacin are known to be dose linear over a broad dose range, including the therapeutically relevant dose levels [2]; however, exposure is dominated by several processes that can potentially be influenced by physiological changes associated with disease, maturation or aging. In this context, physiologically-based pharmacokinetic (PBPK) modelling can be used to assess the effects of physiological and pathophysiological changes, such as process maturation and disease status, on the pharmacokinetics of ciprofloxacin.

Ciprofloxacin is categorized as a class II/IV borderline compound in the Biopharmaceutics Classification System (BCS) [3, 4]. After absorption and the subsequent first-pass effect mainly characterized by oxidative metabolism, ciprofloxacin achieves relatively high concentrations in bronchial tissue [5], prostatic fluid [6] and cerebrospinal fluid [7]. Several mechanisms are involved in its elimination, where $50-80 \%$ is renally excreted. Tubular secretion is the dominant process in the renal elimination of ciprofloxacin [8, 9]. Approximately $20 \%$ of intravenously administered ciprofloxacin undergoes metabolism, and four metabolites have been measured in plasma [10]. The remaining elimination pathway has been described as a transluminal secretion across the enteric mucosa $[8,11]$.

In order to assess ciprofloxacin pharmacokinetics, compartmental modelling and simulation approaches have been described in the literature. Population modelling, with subsequent covariate analysis, has been used to describe the pharmacokinetics of ciprofloxacin in pediatrics and adults [12-14]. Generally, such a modelling approach is well-suited for interpolating simulations, but can generate biased predictions if applied outside of the tested dose or covariate range.

As an alternative, PBPK models integrate a large amount of substance-independent prior knowledge and are therefore particularly suited for questions involving extrapolation beyond tested settings. Generally, limited a priori pharmacokinetic data is required for initial PBPK model building, although observed exposure results are useful to iteratively refine or examine the consistency of the model [15]. A thorough mechanistic understanding of compound pharmacokinetic drivers can help to plan or provide dosing recommendations during concomitant antibiotic pharmacotherapy. The power of PBPK tools led to an increased number of sponsor submissions combining several factors impacting patient pharmacokinetics, such as age, race, genetics and organ impairment [16].

The objective of this study was to establish a ciprofloxacin PBPK model in which exposures for a large dose range are represented, considering major intravenous and oral administration schemes. A PBPK model of ciprofloxacin is presented, integrating clinical data from a comprehensive literature survey and individual data from our own clinical studies. Specifically, the established model should allow a reliable prediction of pharmacokinetics over the entire human age range, from term neonates to the oldest old.

\section{Materials and Methods}

\subsection{Data}

At first, a comprehensive review of the published literature was performed focusing on the pharmacokinetic information of ciprofloxacin following intravenous and oral administration in mainly healthy adults. Studies containing measured plasma concentration-time profiles and courses of urinary excretion or the resulting fractions for different pathway contributions were gathered and extracted. In a second search step, pharmacokinetic studies in pediatric and geriatric subjects were screened and analysed. In cases where studies were conducted in patients, the impact of the respective diseases or health conditions on the pharmacokinetics in adults was re-evaluated and excluded if confirmed. Since cystic fibrosis (CF) was identified as a covariate in a population pharmacokinetic analysis [13], studies including CF patients were excluded, as were studies in patients with sepsis [17, 18], organ impairment [18-20], ectomy, or observed during any other surgical procedures [21,22]. Cancer patients were not considered due to contradicting observations derived from small study groups in this highly heterogeneous patient group [23, 24]. Furthermore, the study population should clearly represent a well-defined age group to allow an age-related pharmacokinetic assessment.

In total, 122 clinical studies reporting ciprofloxacin adult pharmacokinetic data published between 1983 and 2017 were screened, of which 69 were considered in this study (see Tables 1, 2 for a list of the identified studies). For the pediatric age range, three studies had been 
Table 1 Patient characteristics and mean pharmacokinetic parameters in ciprofloxacin studies using intravenous dosing reported in the literature

\begin{tabular}{|c|c|c|c|c|c|c|c|c|c|}
\hline \multirow{2}{*}{$\begin{array}{l}\text { Dosage } \\
(\mathrm{mg})\end{array}$} & \multirow[t]{2}{*}{ Regimen } & \multirow{2}{*}{$\begin{array}{l}\text { Infusion } \\
\text { time (min) }\end{array}$} & \multicolumn{4}{|l|}{ Population } & \multirow[t]{2}{*}{ AUC (mg h/L) } & \multirow[t]{2}{*}{$\mathrm{CL}(\mathrm{L} / \mathrm{h})$} & \multirow[t]{2}{*}{ References } \\
\hline & & & $\begin{array}{l}\text { Age, years } \\
\text { (range) }\end{array}$ & $\begin{array}{l}\text { Weight, } \\
\text { kg (range) }\end{array}$ & $n$ & $\begin{array}{l}\text { Females } \\
(\%)\end{array}$ & & & \\
\hline 20 & & 30 & $80.85(60-96)$ & & 20 & 60 & & & {$[28]$} \\
\hline 25 & BID & 10 & (19-45) & (49.9-71.8) & 9 & $\mathbf{0}$ & $0.73 \pm 0.12$ & $1.878 \pm 0.324^{d}$ & [29] \\
\hline 50 & & 3 & $28(21-34)$ & $69.3(61-79)$ & 8 & 0 & $1.45 \pm 0.33$ & $33.72 \pm 7.29$ & {$[30]$} \\
\hline 50 & & 15 & $30(22-34)$ & $67(52-80)$ & 12 & 50 & $1.23 \pm 0.2$ & $41.58 \pm 7.2$ & {$[31]$} \\
\hline 50 & & 15 & $30(22-34)$ & $67.5(51-80.5)$ & 12 & 50 & $1.2 \pm 0.2$ & $41.22 \pm 7.8^{c}$ & {$[32]$} \\
\hline 50 & BID & 10 & (19-45) & (49.9-71.8) & 9 & $\mathbf{0}$ & $1.59 \pm 0.15$ & $1.908 \pm 0.18^{d}$ & [29] \\
\hline 75 & BID & 10 & (19-45) & (49.9-71.8) & 9 & $\mathbf{0}$ & $2.47 \pm 0.4$ & $2.124 \pm 0.408^{d}$ & [29] \\
\hline 100 & & 30 & 23 & 81.5 & 9 & 0 & $2.24 \pm 0.54$ & $0.576 \pm 0.1254^{\mathrm{d}}$ & {$[33]$} \\
\hline 100 & & 3 & $26(21-40)$ & $68(54-85)$ & 12 & 50 & $2.54 \pm 0.51$ & $40.71 \pm 7.01$ & {$[34,35]$} \\
\hline 100 & & 3 & $28(21-34)$ & $69.3(61-79)$ & 8 & 0 & $2.9 \pm 0.36$ & $32.82 \pm 4.344$ & {$[30]$} \\
\hline 100 & & 5 & 29 & 75 & 6 & 0 & & $9.62 \pm 2.29^{\mathrm{d}}$ & {$[36]$} \\
\hline 100 & & 60 & $29.2(23-42)$ & $78.5(65-85)$ & 6 & 0 & $2.81 \pm 0.57$ & $34.02 \pm 5.32$ & {$[37]$} \\
\hline 100 & & 15 & $30(22-34)$ & $67(52-80)$ & 12 & 50 & $2.88 \pm 0.52$ & $36 \pm 8.4$ & {$[31]$} \\
\hline 100 & & 15 & $30(22-34)$ & $67.5(51-80.5)$ & 12 & 50 & $3 \pm 0.5$ & $31.8 \pm 6.24^{c}$ & {$[32]$} \\
\hline 100 & & 30 & $(21-29)$ & & 6 & 0 & & $23 \pm 9.1^{\mathrm{c}}$ & {$[38]$} \\
\hline 100 & & 30 & $(21-29)$ & & 6 & 0 & & $22.5 \pm 8.9^{\mathrm{c}}$ & {$[38]$} \\
\hline 100 & & 30 & $(21-29)$ & & 6 & 0 & $3.94 \pm 1.25$ & $24.6 \pm 10.4^{\mathrm{c}}$ & {$[38]$} \\
\hline 100 & BID & 30 & $(18-46)$ & $(54.8-73)$ & 9 & $\mathbf{0}$ & $3.4 \pm 0.49$ & $30.1 \pm 3.4^{\mathrm{c}}$ & [39] \\
\hline 150 & & 30 & 23 & 81.5 & 9 & $\mathbf{0}$ & $3.36 \pm 0.74$ & $0.5742 \pm 0.1212^{d}$ & {$[33]$} \\
\hline 150 & BID & 30 & $(18-46)$ & $(54.8-73)$ & 9 & 0 & $5.14 \pm 0.77$ & $29.8 \pm 4^{\mathrm{c}}$ & [39] \\
\hline 200 & & 30 & 23 & 81.5 & 9 & 0 & $5.17 \pm 0.87$ & $0.489 \pm 0.0726^{\mathrm{d}}$ & {$[33]$} \\
\hline 200 & & 30 & $24.3(20-30)$ & $78(64-91)$ & 12 & 0 & $5.2021 \pm 1.3916$ & $41 \pm 11.3$ & {$[40]$} \\
\hline 200 & & & $25.4(19-39)$ & $66.6(50-82)$ & 10 & 50 & $5.52 \pm 1.95$ & & {$[41]$} \\
\hline 200 & & 30 & 27 (19-33) & $79(67-83)$ & 12 & $\mathbf{0}$ & $5.37 \pm 0.72$ & $37.92 \pm 4.5$ & [6] \\
\hline 200 & & 10 & $27.1(22-30)$ & $77.3(60.5-89.4)$ & 8 & 0 & $5.97 \pm 0.91$ & $26.8 \pm 5.71^{\mathrm{c}}$ & {$[42]$} \\
\hline 200 & & 10 & $27.125(22-30)$ & 77.3375 (60.5-89.4) & 8 & 0 & & $26.8 \pm 5.7^{\mathrm{c}}$ & {$[43]$} \\
\hline 200 & & 30 & $29.3(21-38)$ & 67.1 & 12 & 50 & $5.73 \pm 1.38$ & $36.66 \pm 8.04$ & [9] \\
\hline 200 & & 20 & $28(23-34)$ & $66(58-73)$ & 10 & 50 & $5.31 \pm 1.12$ & $39.12 \pm 7.98$ & {$[31]$} \\
\hline 200 & BID & 60 & $72.6(65.4-87.6)$ & $65.6(42-101)$ & 17 & 35 & $5.5 \pm 1.8^{\mathrm{a}}$ & $0.588 \pm 0.258^{\mathrm{d}}$ & {$[44]$} \\
\hline 200 & BID & 30 & 72.96 (44-96) & $67.09(40-111)$ & 44 & 95.5 & $13.71 \pm 5.5^{\mathrm{a}}$ & & {$[45]$} \\
\hline 200 & & 30 & $74(57-84)$ & $72(52-80)$ & 17 & 0 & $8.17 \pm 2.62$ & $26.46 \pm 7.02$ & {$[46]$} \\
\hline 200 & & 30 & $74(57-84)$ & $72(50-80)$ & 14 & 0 & $8.79 \pm 2.73$ & $24.42 \pm 6.24$ & {$[6]$} \\
\hline 200 & BID & 60 & 77 (66-90) & 66 (49.1-102.7) & 9 & 78 & $13.3 \pm 4.8$ & $0.2598 \pm 0.1194^{\mathrm{d}}$ & {$[47]$} \\
\hline 200 & & 30 & $(23-32)$ & 75.9 & 12 & $\mathbf{0}$ & $6.38 \pm 1.05$ & $32 \pm 4.77$ & {$[48]$} \\
\hline 200 & & 30 & $(21-29)$ & & 6 & 0 & & $23.7 \pm 5.1^{\mathrm{c}}$ & {$[38]$} \\
\hline 200 & & 30 & $(21-29)$ & & 6 & 0 & & $23.3 \pm 5^{\mathrm{c}}$ & {$[38]$} \\
\hline 200 & & 30 & $(21-29)$ & & 6 & 0 & $7.22 \pm 1.77$ & $25.2 \pm 5.8^{\mathrm{c}}$ & {$[38]$} \\
\hline 200 & & 10 & $(21-29)$ & & 12 & 0 & & $28.5 \pm 4.7^{\mathrm{c}}$ & [49] \\
\hline 200 & BID & 30 & $(18-46)$ & $(54.8-73)$ & 9 & 0 & $7.7 \pm 1.38$ & $26.9 \pm 4.1^{\mathrm{c}}$ & [39] \\
\hline 250 & & 5 & $28(21-34)$ & $69.3(61-79)$ & 8 & $\mathbf{0}$ & $8.11 \pm 0.94$ & $29.28 \pm 3.504$ & {$[30]$} \\
\hline 250 & & 5 & $69(63-76)$ & 76.9 & 8 & 0 & $8.9 \pm 0.83$ & $26.04 \pm 3.222^{\mathrm{c}}$ & {$[50]$} \\
\hline 300 & & 30 & $24.3(20-30)$ & $78(64-91)$ & 12 & 0 & $8.7143 \pm 1.8886$ & $35.7 \pm 5.8$ & {$[40]$} \\
\hline 300 & & 60 & $27.3(21-35)$ & 73 & 12 & $\mathbf{0}$ & $8.6 \pm 1.5$ & $36.18 \pm 7.62$ & {$[51]$} \\
\hline 400 & BID & 30 & $24.3(20-30)$ & $78(64-91)$ & 12 & 0 & $11.0999 \pm 1.0934$ & $36.5 \pm 3.8$ & {$[40]$} \\
\hline 400 & & 60 & 24.7 & 77.3 & 12 & $\mathbf{0}$ & $11.2 \pm 0.672$ & $35.6 \pm 2.136$ & {$[25]$} \\
\hline 400 & & & $25.4(19-39)$ & $66.6(50-82)$ & 10 & 50 & $11.22 \pm 3.5$ & & {$[41]$} \\
\hline
\end{tabular}


Table 1 continued

\begin{tabular}{|c|c|c|c|c|c|c|c|c|c|}
\hline \multirow{2}{*}{$\begin{array}{l}\text { Dosage } \\
(\mathrm{mg})\end{array}$} & \multirow[t]{2}{*}{ Regimen } & \multirow{2}{*}{$\begin{array}{l}\text { Infusion } \\
\text { time (min) }\end{array}$} & \multicolumn{4}{|l|}{ Population } & \multirow[t]{2}{*}{ AUC (mg h/L) } & \multirow[t]{2}{*}{$\mathrm{CL}(\mathrm{L} / \mathrm{h})$} & \multirow[t]{2}{*}{ References } \\
\hline & & & $\begin{array}{l}\text { Age, years } \\
\text { (range) }\end{array}$ & $\begin{array}{l}\text { Weight, } \\
\text { kg (range) }\end{array}$ & $n$ & $\begin{array}{l}\text { Females } \\
(\%)\end{array}$ & & & \\
\hline 400 & TID & 60 & 25.75 & 74.95 & 12 & 50 & $8.75 \pm 1.165$ & $31.5 \pm 5.355$ & [25] \\
\hline 400 & & 60 & 26.8 & 60.2 & 12 & 100 & $14.4 \pm 2.304$ & $27.7 \pm 4.432$ & [25] \\
\hline 400 & & 60 & 27.3 & $74.9(63.3-84.5)$ & 6 & 0 & $14.2 \pm 1.1$ & & [52] \\
\hline 400 & & 60 & $27.3(21-35)$ & 73 & 12 & 0 & $11.4 \pm 1.6$ & $35.82 \pm 4.92$ & [51] \\
\hline 400 & & 60 & 28.2 & 73.3 & 18 & 0 & $24.2 \pm 5.1^{\mathrm{b}}$ & $51.72 \pm 11.28^{\mathrm{c}}$ & [53] \\
\hline 400 & TID & 60 & 28.2 & 73.3 & 18 & 0 & $32.9 \pm 8.83^{\mathrm{b}}$ & $38.94 \pm 9.96^{\mathrm{c}}$ & [53] \\
\hline 400 & & 60 & 67.7 & 90 & 12 & 0 & $13.7 \pm 0.822$ & $29.2 \pm 1.752$ & {$[25]$} \\
\hline 400 & BID & 60 & 68.25 & 73.3 & 12 & 50 & $0 \pm 0$ & $24.8 \pm 5.208$ & [25] \\
\hline 400 & & 60 & 68.8 & 67.9 & 12 & 100 & $19 \pm 3.23$ & $21.1 \pm 3.587$ & {$[25]$} \\
\hline
\end{tabular}

Bold values indicates studies used for model building

$B I D$ twice daily, $T I D$ three times daily, $A U C$ area under the plasma concentration-time curve, $A U C_{12}$ AUC from time zero to $12 \mathrm{~h}, A U C_{24} \mathrm{AUC}$ from time zero to $24 \mathrm{~h}, C L$ clearance

${ }^{\mathrm{a}} \mathrm{AUC}_{12}$

${ }^{\mathrm{b}} \mathrm{AUC}_{24}$

${ }^{\mathrm{c}}$ Clearance normalized to body surface area $\left(\mathrm{L} / \mathrm{h} / 1.73 \mathrm{~m}^{2}\right)$

${ }^{\mathrm{d}}$ Clearance normalized to body weight $(\mathrm{L} / \mathrm{h} / \mathrm{kg})$

identified, while 11 studies were gathered for the geriatric age group (summarized in Table 3).

In addition to mean study data, individual plasma concentration-time profiles were gathered for pediatric and geriatric patients. For the children, parts of a previously published data-driven population modelling dataset were used [13]. CF patients were discarded from the dataset, resulting in 236 (143 male and 93 female) children being included in this study. The individuals were treated for various infections and received $10 \mathrm{mg} / \mathrm{kg}$ twice daily orally or three times daily intravenously. In total, 763 plasma concentration-time data points sampled in non-CF children were available for this study.

Adult and geriatric individual plasma concentrationtime profiles were obtained from three trials [25-27]. The 22 older adults were aged between 60 and 74 years and received $400 \mathrm{mg}$ three times daily intravenously, or a single $250 \mathrm{mg}$ oral dose.

\subsection{Physiologically-Based Pharmacokinetic (PBPK) Model Development of Ciprofloxacin}

A whole-body PBPK ciprofloxacin model was built using the open source modeling software Open Systems Pharmacology Suite (OSP Suite, http://www.open-systemspharmacology.org), which comprises the PBPK software tool PK-Sim ${ }^{\circledR}$ version 7.2.0, and the systems biology platform MoBi, which allows in-depth mechanistic modeling. The generic PBPK software tool represents 18 organs and tissues and provides a large dataset for agedependent anatomical and physiological parameters over the entire human lifespan [15]. Parameter optimization was conducted in MATLAB ${ }^{\circledR}$ version R2013b using the Monte Carlo algorithm of the 'Parameter Identification (PI) Toolbox'.

\subsubsection{Intravenous Administration}

The ciprofloxacin PBPK model-building process was performed stepwise, as depicted in the workflow shown in Fig. 1. First, physicochemical data available in the literature were incorporated into an initial adult PBPK model. Reported mass-balance data suggest $65.3 \%$ urinary and $11.4 \%$ faecal excretion of unchanged ciprofloxacin after a 7-day recovery period following intravenous administration, while $19.6 \%$ of the dose accounted for metabolites and $2.7 \%$ were unaccounted for [8]. Considering the reported mass-balance information, two first-order hepatic and two renal clearance processes were implemented in the model. Renal clearance processes included a passive glomerular filtration rate (GFR) and an unspecific firstorder tubular secretion to account for the renal clearance exceeding GFR. The active process was left unspecific, although the contribution of several transporters, such as the ATP-binding cassette (ABC) drug efflux transporter family [89] or organic anion transporter (OAT) [90], are 


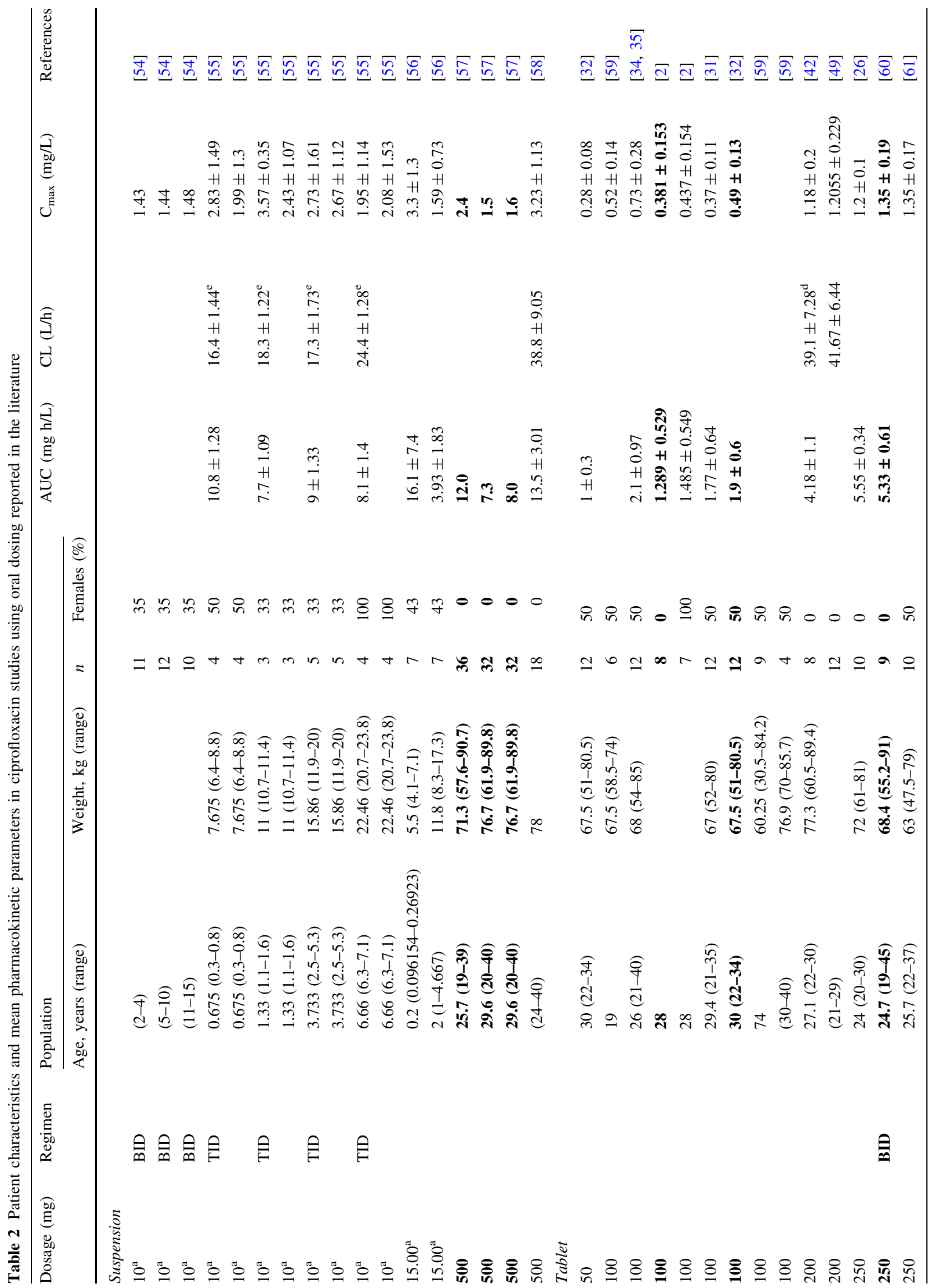




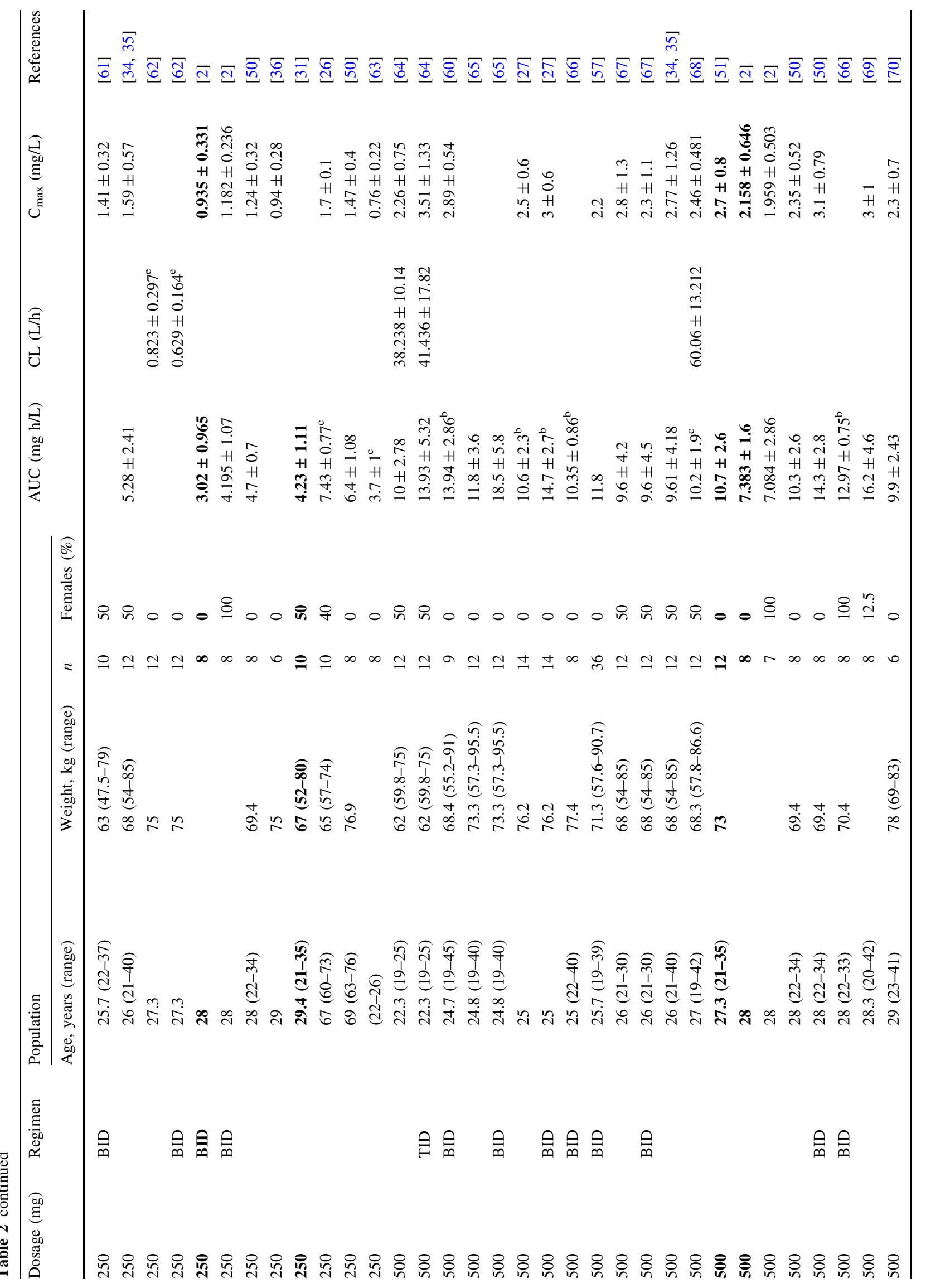




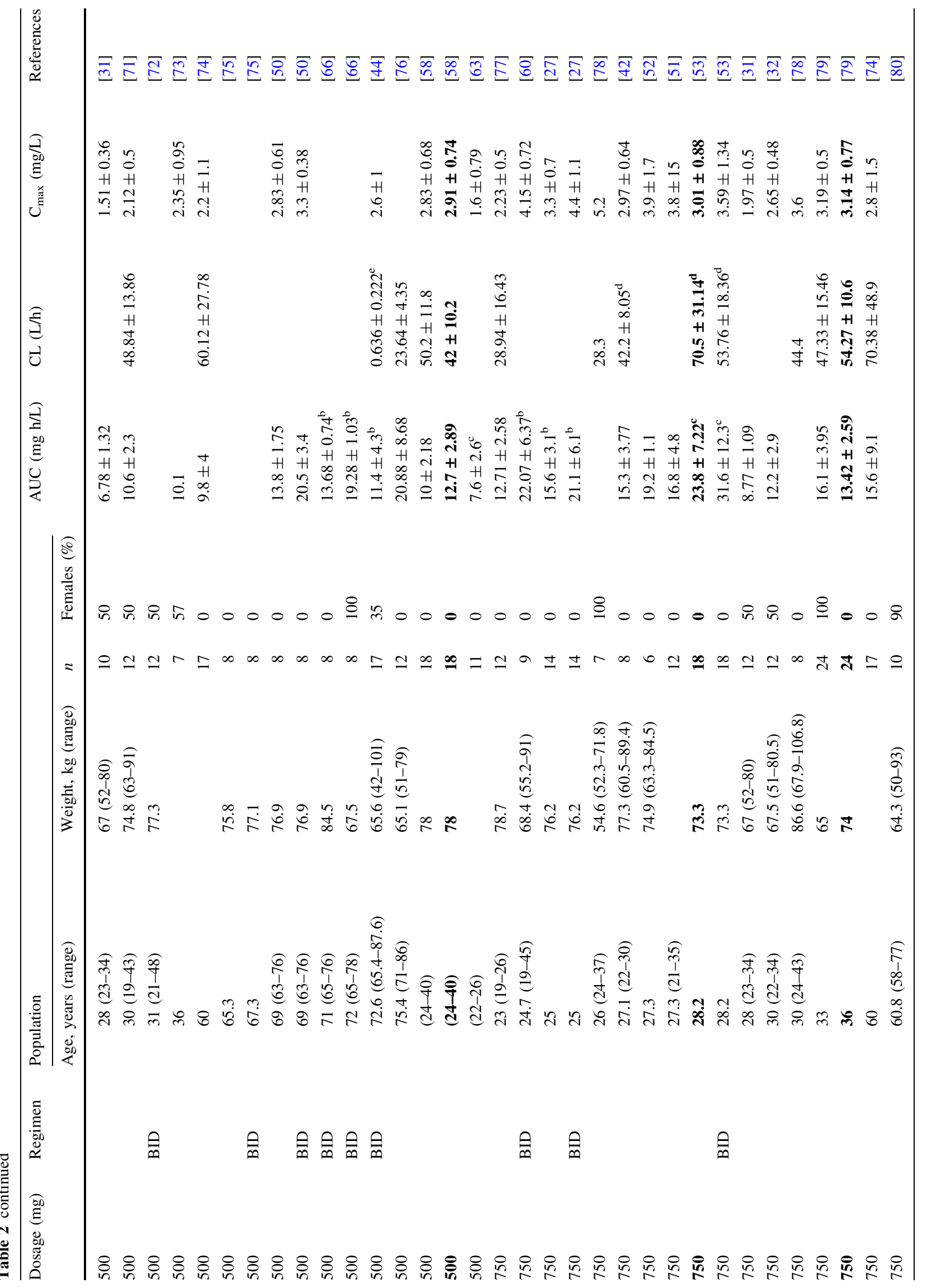




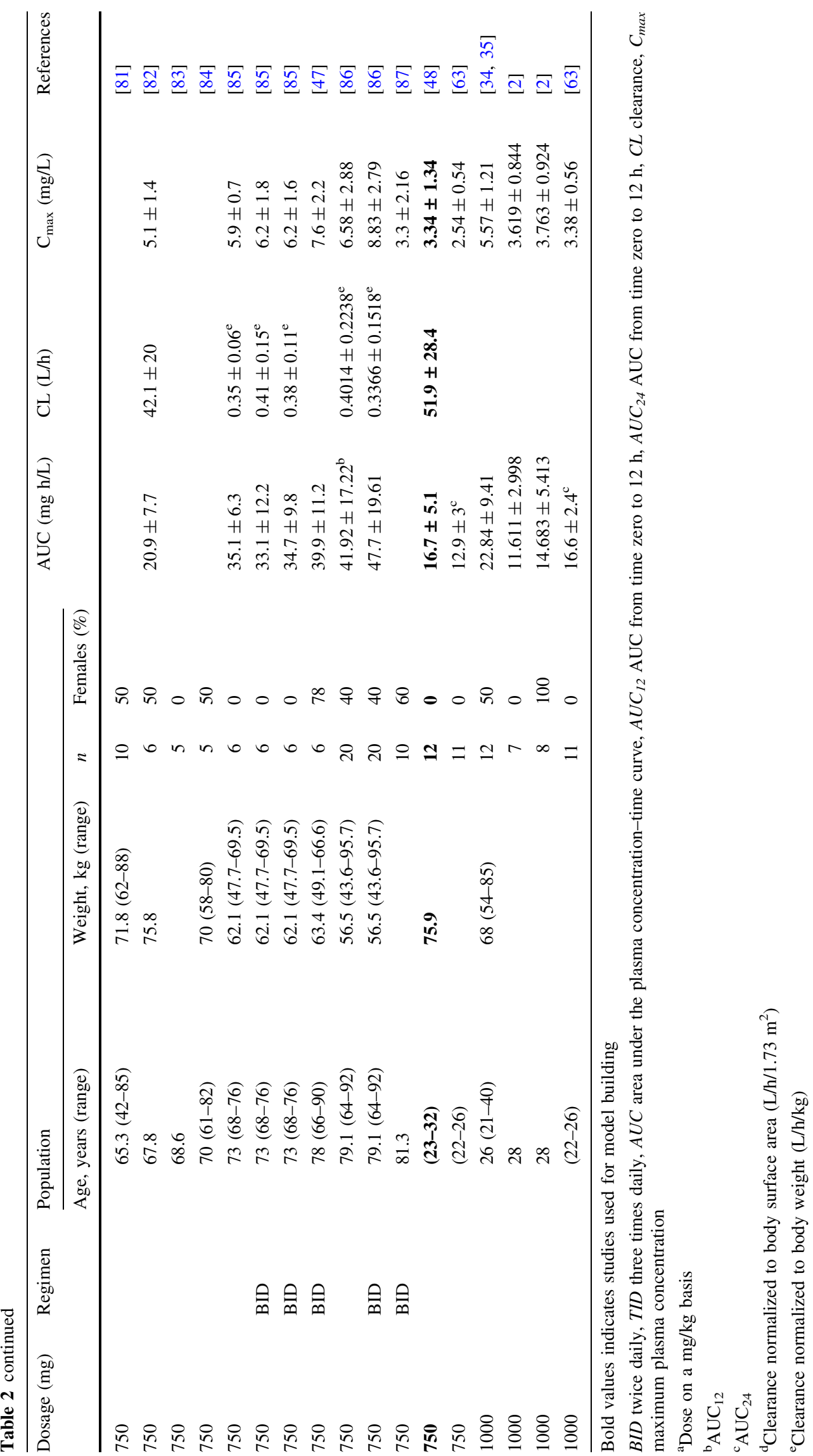


Table 3 Summary of clinical studies of ciprofloxacin, sorted by dose, in pediatrics and older adults, used to define the prediction scenarios in this study and compare the predictive performance of the ciprofloxacin PBPK model

\begin{tabular}{|c|c|c|c|c|c|c|c|c|c|c|c|c|c|}
\hline \multirow{2}{*}{$\begin{array}{l}\text { Age } \\
\text { group }\end{array}$} & \multicolumn{7}{|c|}{ Population } & \multicolumn{5}{|c|}{ Dosage } & \multirow[t]{2}{*}{ References } \\
\hline & Age & & & $\begin{array}{l}\text { Females } \\
(\%)\end{array}$ & $\begin{array}{l}\text { Weight, kg } \\
\text { (range) }\end{array}$ & $\begin{array}{l}\text { Height, } \mathrm{cm} \\
\text { (range) }\end{array}$ & $n$ & Route & Formulation & $\mathrm{mg}$ & $\begin{array}{l}\mathrm{mg} / \\
\mathrm{kg}\end{array}$ & Regimen & \\
\hline \multirow[t]{5}{*}{ Pediatrics } & 2 & 15 & Years & 35 & & & 60 & IV & Suspension & & 10 & BID & {$[88]$} \\
\hline & 0.7 & 70.1 & Years & 54 & $\begin{array}{l}14.3 \\
\quad(6.4-23.8)\end{array}$ & $90.5(65-126)$ & 16 & IV & Suspension & & 10 & TID & {$[55]$} \\
\hline & 2 & 15 & Years & 35 & $\begin{array}{l}72.1 \\
\quad(66.8-78.8)\end{array}$ & & 60 & $\mathrm{PO}$ & Suspension & & 10 & BID & {$[54]$} \\
\hline & 5 & 14 & Weeks & 43 & $5.5(4.1-7.1)$ & & 7 & $\mathrm{PO}$ & Unknown & & 15 & & {$[56]$} \\
\hline & 1 & 5 & Years & 43 & $\begin{array}{l}11.8 \\
\quad(8.3-17.3)\end{array}$ & & 7 & $\mathrm{PO}$ & Unknown & & 15 & & {$[56]$} \\
\hline \multirow[t]{18}{*}{ Elderly } & 66 & 90 & Years & 78 & $\begin{array}{l}66 \\
\quad(49.1-102.7)\end{array}$ & $\begin{array}{l}168 \\
\quad(149-182)\end{array}$ & 9 & IV & Unknown & 200 & & & [47] \\
\hline & 57 & 84 & Years & 0 & $69(52-80)$ & $\begin{array}{l}168 \\
(155-175)\end{array}$ & 14 & IV & Unknown & 200 & & & [46] \\
\hline & 67 & 83 & Years & 0 & $72(50-80)$ & & 14 & IV & Solution & 200 & & & {$[6]$} \\
\hline & 65 & 87 & Years & 35 & $65.6(42-101)$ & & 17 & IV & Solution & 200 & & BID & [44] \\
\hline & 44 & 96 & Years & 95.5 & $\begin{array}{l}67.09 \\
\quad(40-111)\end{array}$ & $\begin{array}{l}160 \\
(150-178)\end{array}$ & 44 & IV & Solution & 200 & & BID & [45] \\
\hline & 63 & 76 & Years & 0 & 76.9 & & 8 & IV & Solution & 250 & & & {$[50]$} \\
\hline & 67 & 83 & Years & 0 & & & 6 & IV & Solution & 400 & & TID & {$[25]$} \\
\hline & 67 & 83 & Years & 100 & & & 6 & IV & Solution & 400 & & TID & {$[25]$} \\
\hline & 60 & 73 & Years & 40 & $65(57-74)$ & & 10 & $\mathrm{PO}$ & Tablet & 250 & & & {$[26]$} \\
\hline & 71 & 86 & Years & 0 & $65.1(51-79)$ & $\begin{array}{l}161 \\
\quad(154-170)\end{array}$ & 12 & $\mathrm{PO}$ & Tablet & 500 & & & [76] \\
\hline & 63 & 76 & Years & 0 & 76.9 & & 8 & $\mathrm{PO}$ & Tablet & 500 & & & {$[50]$} \\
\hline & 65 & 87 & Years & 35 & $65.6(42-101)$ & & 17 & $\mathrm{PO}$ & Tablet & 500 & & BID & [44] \\
\hline & 63 & 76 & Years & 0 & 76.9 & & 8 & $\mathrm{PO}$ & Tablet & 500 & & BID & {$[50]$} \\
\hline & 68 & 76 & Years & 0 & $\begin{array}{l}62.1 \\
\quad(47.7-69.5)\end{array}$ & & 6 & $\mathrm{PO}$ & Tablet & 750 & & BID & {$[85]$} \\
\hline & 61 & 82 & Years & 0 & $70(58-80)$ & & 15 & $\mathrm{PO}$ & Tablet & 750 & & & [84] \\
\hline & 64 & 92 & Years & 40 & $\begin{array}{l}56.5 \\
\quad(43.6-95.7)\end{array}$ & & 20 & $\mathrm{PO}$ & Tablet & 750 & & BID & {$[86]$} \\
\hline & 58 & 77 & Years & 10 & $64.3(50-93)$ & & 10 & $\mathrm{PO}$ & Unknown & 750 & & & {$[80]$} \\
\hline & 66 & 90 & Years & 78 & $\begin{array}{l}63.4 \\
\quad(49.1-66.6)\end{array}$ & $\begin{array}{l}168 \\
(149-182)\end{array}$ & 6 & $\mathrm{PO}$ & Unknown & 750 & & & [47] \\
\hline
\end{tabular}

$B I D$ twice daily, $T I D$ three times daily, $I V$ intravenously, $P O$ orally, $P B P K$ physiologically-based pharmacokinetic

discussed but not finally elucidated. Besides a first-order hepatic metabolism mediated by cytochrome P450 (CYP) 1A2 [91], an additional unspecific biliary secretion was included. The latter process accounts for a suggested rapid gastrointestinal transcellular secretion of ciprofloxacin $[8,11]$. Concurrently, biliary duct concentration exceeds plasma levels by 20-fold [92]. The resulting luminal concentrations were consolidated by a continuous fraction of bile released into the gut. Less than $3 \%$ of the mass-balance information was not accounted for and was proportionally distributed across all elimination processes.

\subsubsection{Oral Administration and Formulation}

The mechanistic absorption model in PK-Sim ${ }^{\circledR}$ allows identification of different factors contributing to the ratelimiting impact on the oral absorption of ciprofloxacin. Therefore, active uptake and dissolution profiles were estimated based on concentration-time profiles after oral administration of solution, suspension and immediate-release formulations containing $100-750 \mathrm{mg}$ active ingredient. Since intestinal permeability $\left(P_{\text {int }}\right)$ is a global parameter of the gastrointestinal tract in $\mathrm{PK}-\mathrm{Sim}^{\circledR}$, the effective surface area enhancement factor $\left(A_{\text {eff }}\right.$ Factor), a 
Fig. 1 Schematic workflow of the ciprofloxacin PBPK model building and verification steps, including estimated parameters, incorporated data and model verification steps. $i v$ intravenous, po per os (orally), CYP cytochrome $\mathrm{P} 450, P B P K$ physiologically-based pharmacokinetic

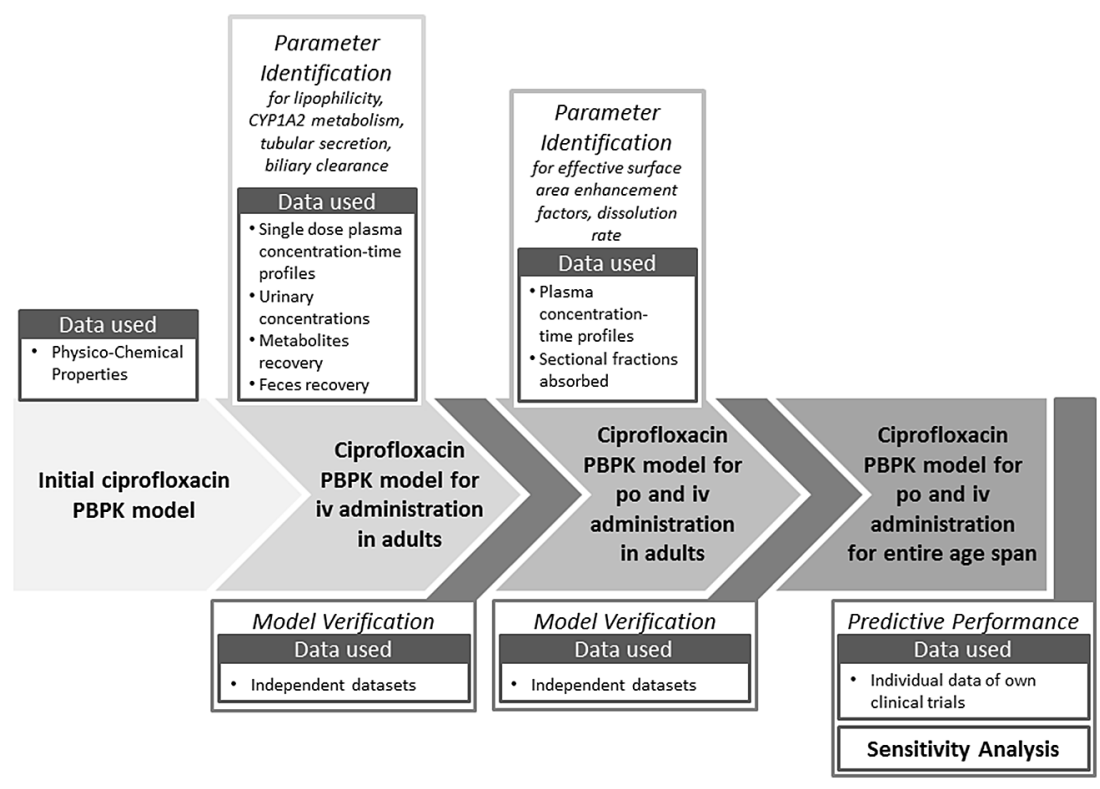

multiplier of $P_{\text {int }}$ in each intestinal segment of the gastrointestinal tract [93], was estimated for each segment. By this, segmental net absorption impacted by active influx or efflux, and deviating from the estimated passive absorption, can be accounted for by a respective increase or decrease of each $A_{\text {eff }}$ Factor. Finally, in vivo dissolution was informed for each dosage form and dose level. The formulation and subsequent granulate disintegration and dissolution for each dosage form was estimated and was assumed to follow a Weibull function. Similarly to parenteral administration, observed plasma concentrationtime profiles following single and multiple administrations of oral doses were pooled for the PI. This allowed for separation of formulation- or gastrointestinal tract-dependent influences.

\subsection{PBPK Model Verification}

In order to verify the adult intravenous and oral administration model of ciprofloxacin, population simulations in adult reference populations were compared with independent datasets (Tables 1, 2). Population simulations for each study and dosing scenario contained 1000 individuals matching the respective study characteristics. Performance of the adult ciprofloxacin PBPK model was assessed visually by goodness-of-fit plots for intravenous and oral administration for mean plasma concentration-time study data. Furthermore, the infinite and timely limited area under the plasma drug concentration-time curve $\left(\mathrm{AUC}_{\infty}\right.$ and $\mathrm{AUC}_{\tau}$ ), and, additionally for oral administration, the maximum plasma concentration $\left(C_{\max }\right)$, were determined using the non-compartmental approach of PK-Sim ${ }^{\circledR}$. Mean model simulations were compared with mean literature observations. For all ratio tests, model performance was evaluated by applying the bioequivalence criteria of 1.25fold and the common twofold criteria for simulation scenarios inside and predictions outside the model-building age range.

\subsection{Scaling of the Adult Model for Predictions in Pediatric and Geriatric Patients}

Once the final adult ciprofloxacin PBPK model was verified, exposure resulting from different dosing scenarios for both ends of the age scale outside of the previously simulated range were predicted by applying the underlying anatomical and physiological age dependencies, as well as age-related clearance and protein-binding information [94-96]. The predictions were carried out without any adjustment of substance-specific parameters defined for the adult reference ciprofloxacin model.

Scaling of the implemented clearance processes to the pediatric population age range was based on a previously published analysis [94]. For scaling to older adults, the active tubular secretion process was assumed to decrease proportionally to the GFR with increasing age. Therefore, the aging function of the implemented unspecific tubular secretion is linked to the aging GFR [96]. The hepatic elimination processes mediated by CYP1A2 and the unspecific biliary secretion were scaled in comparison with adult capability on a per-organ weight basis for the elderly population. This indirect scaling considers the age-dependent changes in liver size and perfusion, protein binding and hematocrit [96].

Formulation information derived during the modelbuilding process for adults was carried forward for the 
predictions in pediatrics and older adults. Age-dependent information on gastric emptying time, the $\mathrm{pH}$ of the gastrointestinal tract, small intestinal transit times, and the intestinal surface area were applied as defined in the underlying OSP database and as previously published [97]. Since the specific transporters contributing to the absorption and elimination of ciprofloxacin have not yet been fully elucidated, the effect of the maturation and aging process on these pathways is unknown. The resulting uncertainty can be minimized based on respective GI-tract measure changes over age since transporter abundance is normalized to the surface area [93].

The scaled prediction scenarios were generated based on the available literature data for clinical observations in children and older adults, as summarized in Table 3. Whenever the specific formulation administered was not stated in the respective study, the use of a single immediate-release tablet for the respective fixed dose, and a solution for a body weight-based dose, was assumed for the prediction.

The previously described model verification tests were also performed to allow a predictive performance analysis for scaling to the investigated age ranges. Additionally, AUC and $C_{\max }$ predictions over the entire lifespan were compared with clinically observed data.

\subsection{Sensitivity Analysis}

The impact of certain parameter changes was estimated in a sensitivity analysis (SA) for simulated $C_{\max }$ following oral administration and AUC for representative individuals characterizing different regions in parameter space. Investigating parameter influences on outputs serve as an indicator for model performance, reliability and significance of the results achieved.

The SA covered the entire age range assessed in this simulation study and was calculated for all 136 nonderived model parameters. The remaining parameters in the PBPK model are derived from these and are therefore investigated implicitly. Following the US FDA age grouping [98], age classes were defined for the pediatric age range, and continued with 10-year age increments from 30 years to the oldest old.

Parameters contributing to reach a cut-off defined by capturing $90 \%$ of the cumulated total sensitivity were discussed. Since the sum, as well as the identified parameters within this range, might differ between the analyzed age groups, common and deviating parameters within this range were considered. A detailed description of the SA is provided in the electronic supplementary material.

\section{Results}

According to the previously defined PBPK model building, verification, and scaling workflow in Fig. 1, the model was parameterized based on experimental data in adults for intravenous and oral administration of ciprofloxacin. The model was then scaled to the pediatric and geriatric age range, considering age-dependent physiological changes. For both ends of the age scale, previously studied dosing scenarios were predicted based on prior knowledge, and subsequently compared with the observed exposure.

\subsection{Intravenous Ciprofloxacin PBPK Model Simulations for Adults}

Parameters describing the drug distribution (octanol-water partition coefficient- $\log P$ ), metabolism (CYP1A2), and elimination (tubular secretion and biliary clearance) processes were identified based on human plasma concentration-time data, mass-balance information, and urinary excretion profiles following single or multiple intravenous administration of doses ranging from 25 to $400 \mathrm{mg}$. Studies applied for this step are reported in Table 1. The results of the multiparametric fit to inform the lipophilicity as well as the metabolism and elimination processes, are listed in Table 4. The correlation matrix for this fit (shown in electronic supplementary Fig. 1) revealed no or weak correlations between the three pathways and the lipophilicity, but a stronger correlation between the two hepatic pathways. Since the mass-balance data were used to inform the PI, the retrieved pathway parameterization was accepted for further application.

In a subsequent application, the developed ciprofloxacin PBPK model for intravenous administration in adults was able to well describe the plasma concentration-time profiles following different intravenous administration protocols. An exemplary profile is shown in Fig. 2.

\subsection{Oral Ciprofloxacin PBPK Model Simulations for Adults}

After the ciprofloxacin PBPK model was parameterized for intravenous administration in adults, the model was expanded to simulate oral absorption from the gastrointestinal tract. Following the multiparametric fit, the respective parameters were adjusted, as shown in Table 4 and electronic supplementary Table 1 , where estimated parameters were not, or only weakly, correlated (electronic supplementary Fig. 2). The subsequent simulations of plasma concentration-time profiles for ciprofloxacin doses ranging from 50 to $1000 \mathrm{mg}$ were sufficiently reliable compared with experimental data. Although different 
Table 4 Input data values and model parameters for the ciprofloxacin PBPK model

\begin{tabular}{|c|c|c|}
\hline \multirow[t]{2}{*}{ Parameter } & \multicolumn{2}{|c|}{ Ciprofloxacin PBPK model } \\
\hline & Model input value & Sources \\
\hline \multicolumn{3}{|l|}{ Physicochemical } \\
\hline Molecular mass $(\mathrm{g} / \mathrm{mol})$ & 331.3 & Drugbank (http://www.drugbank.ca) \\
\hline $\log P$ & 0.95 & Estimated using PK-Sim ${ }^{\circledR}$ parameter identification \\
\hline \multirow[t]{2}{*}{$\mathrm{pKa}$} & 6.09 (acidic) & Experimentally determined [99] \\
\hline & 8.62 (basic) & Experimentally determined [99] \\
\hline Fraction unbound & 0.67 & Experimentally determined [31] \\
\hline Aqueous solubility at $\mathrm{pH} 7(\mathrm{mg} / \mathrm{mL})$ & 38.4 & Experimentally determined $[100]$ \\
\hline \multicolumn{3}{|l|}{ Absorption } \\
\hline \multicolumn{3}{|l|}{ Enhancement factor } \\
\hline Duodenum & 255.8 & Estimated using PK-Sim ${ }^{\circledR}$ parameter identification \\
\hline Upper and lower jejunum & 10.4 & Estimated using PK-Sim ${ }^{\circledR}$ parameter identification \\
\hline Upper and lower ileum & 11.0 & Estimated using PK-Sim ${ }^{\circledR}$ parameter identification \\
\hline Large intestine & 2.3 & Estimated using PK-Sim ${ }^{\circledR}$ parameter identification \\
\hline \multicolumn{3}{|l|}{ Distribution } \\
\hline Partition coefficient model & PK-Sim standard & Willmann et al. $[101,102]$ \\
\hline Cellular permeability model & PK-Sim standard & Willmann et al. $[101,102]$ \\
\hline \multicolumn{3}{|l|}{ Metabolism } \\
\hline CYP1A2-mediated clearance (L/min) & 0.067 & Estimated using PK-Sim ${ }^{\circledR}$ parameter identification \\
\hline \multicolumn{3}{|l|}{ Elimination pathways } \\
\hline GFR fraction for passive renal clearance & 1 & PK-Sim ${ }^{\circledR}$ default \\
\hline Tubular secretion clearance (L/min) & 0.706 & Estimated using PK-Sim ${ }^{\circledR}$ parameter identification \\
\hline Biliary clearance $(\mathrm{mL} / \mathrm{min} / \mathrm{kg})$ & 1.286 & Estimated using PK-Sim ${ }^{\circledR}$ parameter identification \\
\hline
\end{tabular}

$\log P$ octanol-water partition coefficient, $p K a$ acid dissociation constant in log scale, GFR fraction fraction of glomerular filtration rate used for passive renal elimination, $C Y P$ cytochrome $\mathrm{P} 450, P B P K$ physiologically-based pharmacokinetic

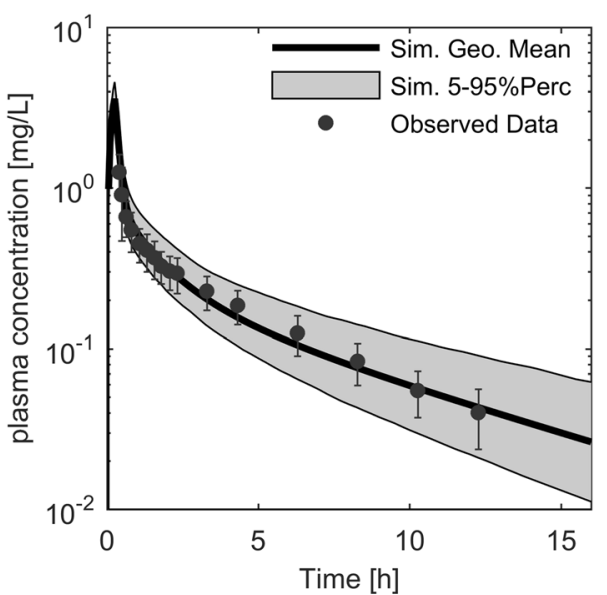

Fig. 2 Exemplary ciprofloxacin plasma concentration-time profile after a $200 \mathrm{mg}$ intravenous administration (left). The symbols (black dots) represent the median of the individually observed plasma concentration, with the corresponding standard deviation indicated by error bars [31]. The thick black line represents the simulated population median, and the grey shaded area covers the 5th to 95th

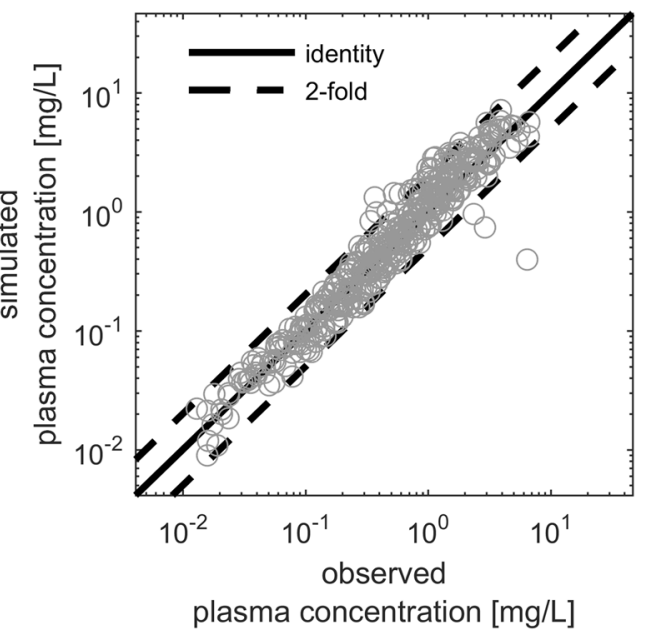

percentile prediction interval of simulated plasma concentration-time profiles. The simulated versus observed study population mean plasma concentration-time points (right) were used for model verification in the adult age range. In this figure, the thick black line represents the line of identity and the dashed lines indicate the twofold range 
properties for formulations were identified, the fraction dissolved was almost complete and a fraction absorbed of nearly $80 \%$ was achieved, allowing bioavailability of approximately $70 \%$. The formulations differed in the initial phase after absorption, leading to differences within the bioequivalence range for the time at which $C_{\max }$ occurred. An exemplary profile is shown in Fig. 3.

\subsection{PBPK Model Verification}

The ciprofloxacin PBPK model for adults was verified by comparing independent datasets that were not used for model building, with corresponding simulations. Reliable simulations were obtained for the mean plasma concentration-time data after intravenous and oral administration, as visualized in Figs. 2 and 3. Only $4.82 \%$ of the mean observed data points for intravenous administration, and $12.13 \%$ for oral administration, were outside the simulated twofold range, with no concentration-related bias.

The comparison of AUC and $C_{\max }$ with literature observations showed no bias for the respective doses (Fig. 4). Figure 4 illustrates that variability in AUC is higher in oral dosing compared with intravenous dosing: four simulated-to-observed AUC ratios were outside the 1.25-fold range after intravenous dosing, compared with 21 of 44 after oral dosing. Furthermore, all $C_{\max }$ ratios for oral administration were within the twofold range, while 10 of the 21 ratios were outside the 1.25 -fold range. These results showed that, overall, the PBPK model is well-suited to describe the pharmacokinetics of ciprofloxacin after intravenous and oral administration in adults.

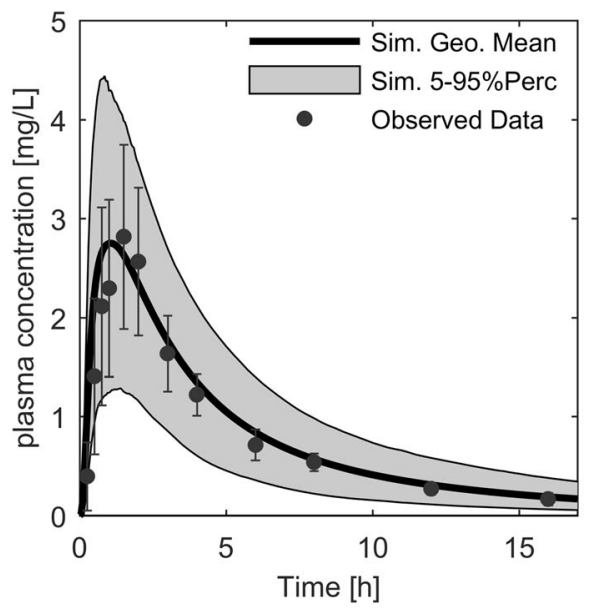

Fig. 3 Exemplary ciprofloxacin plasma concentration-time profile after a $500 \mathrm{mg}$ oral administration (left). The symbols (black dots) represent the median of the individually observed plasma concentration, with the corresponding standard deviation indicated by error bars [79]. The thick black line represents the simulated population median, and the grey shaded area covers the 5 th-95th percentile prediction

\subsection{Prediction of the Age-Related Impact on Ciprofloxacin Pharmacokinetics}

Considering the physiological changes related to maturation and aging of the human body, the ciprofloxacin PBPK model was scaled to both ends of the age scale. The model successfully predicted the ciprofloxacin plasma pharmacokinetic profiles from 3 months to 90 years of age. Mean data points for both intravenous and oral administration were well-predicted, with only 7.61 and $5.56 \%$ of the predictions outside the twofold range having no concentration-related bias (Fig. 5).

Predicting the exposure of several dosing schemes in different pediatric age groups and overlay plots with observed data revealed wider variability for the clinical observations. Towards the younger ages, $C_{\max }$ was wellpredicted for the population mean, but showed some extremely high concentrations; however, the model was able to cover these concentrations with the predicted concentration range. Deviation was less pronounced for the adult and geriatric population following oral administration (Fig. 6). Overall, on a population level, the ciprofloxacin PBPK model was able to well-predict the exposure and respective shifts over the entire lifespan, as shown in Fig. 7.

\subsection{Sensitivity Analysis}

The parameter SA shown in Fig. 8 revealed that, among all model parameters, dose had the highest and most equal impact on the pharmacokinetic measures $\mathrm{AUC}_{\infty}$ and $C_{\max }$

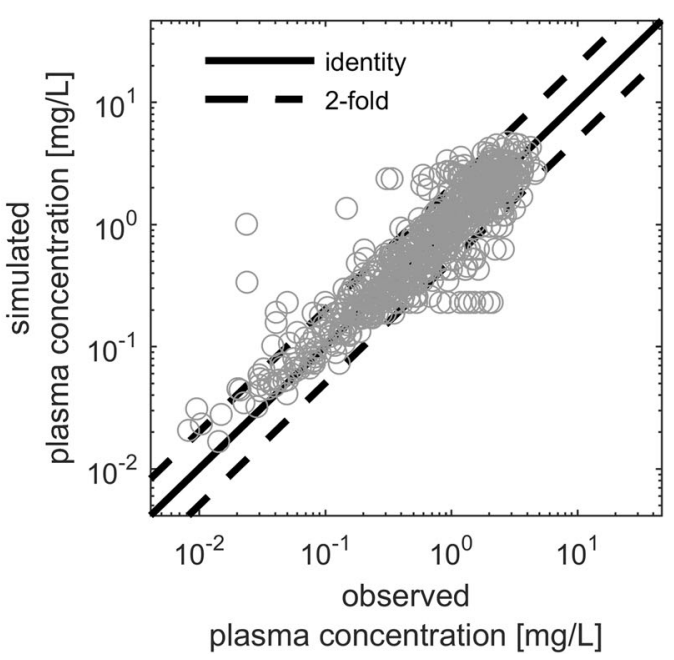

interval of simulated plasma concentration-time profiles. The simulated versus observed study population mean plasma concentrationtime points (right) were used for model verification in the adult age range. In this figure, the thick black line represents the line of identity, and the dashed lines indicate the twofold range 
for all age groups, followed by the unbound fraction and parameters related to clearance pathways. For $\mathrm{AUC}_{\infty}$, agerelated patterns were observed for the impact of metabolism and excretion pathways. While the impact of the mainly hepatically located CYP metabolism and biliary secretion increased towards younger age groups, the renally mediated tubular secretion had a greater impact towards older age groups. More parameters contributed to achieve $90 \%$ of the cumulated total sensitivity for $C_{\max }$. In addition to parameters relating to metabolism and elimination, distribution-related parameters were more impor-
Fig. 6 Comparison of predicted (solid lines; geometric mean, shaded area; 5-95th percentile deviation, dashed lines; minimum and maximum) and individual observed data (dots) concentrations of intravenous (left panel) and oral (right panel) administration of ciprofloxacin after a dose of $10 \mathrm{mg} / \mathrm{kg}$ every $8 \mathrm{~h}$ in pediatric patients of different ages: 0-1 year (a), 1-2 years (b), 2-6 years (c), and 6-12 years (d). Intravenous doses in adults (e, left) and geriatric patients (f, left) were $400 \mathrm{mg}$, while oral dosing in adults was $750 \mathrm{mg}$ (e, right) and $250 \mathrm{mg}$ in geriatric patients (f, right). The time indicates the time after the first dose (before axis break) and at steady-state (after axis break). Observed data are based on previous studies $[13,25-27,55,103]$
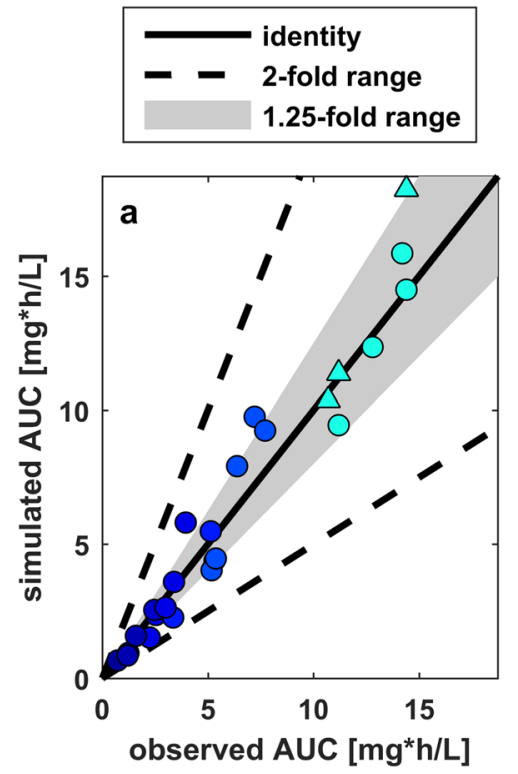
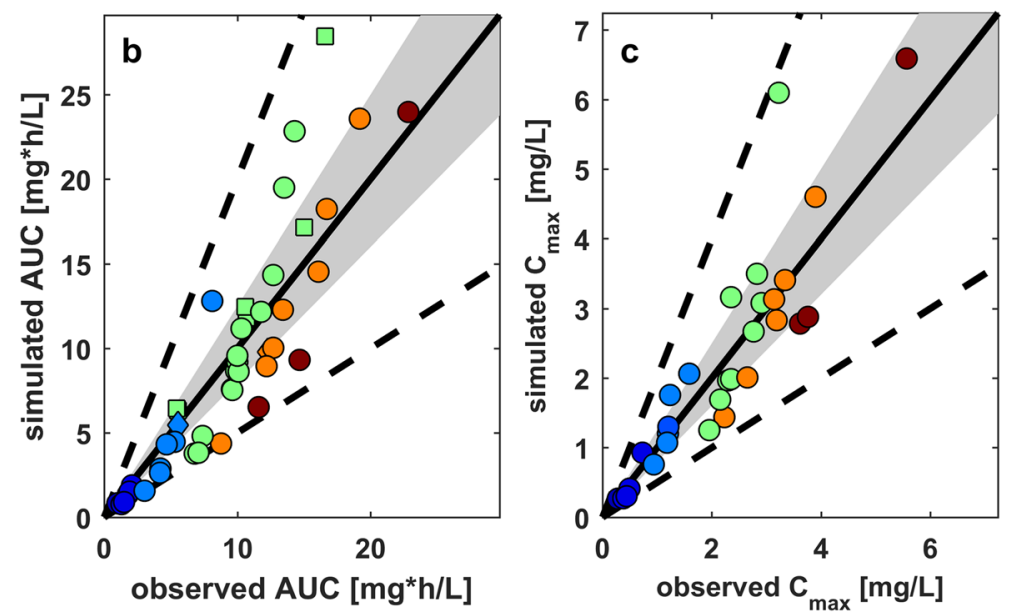

- $25 \mathrm{mg}$

- $50 \mathrm{mg}$

- $75 \mathrm{mg}$

- $100 \mathrm{mg}$

- $150 \mathrm{mg}$

- $200 \mathrm{mg}$

○ $250 \mathrm{mg}$

○ $400 \mathrm{mg}$

○ $500 \mathrm{mg}$

$750 \mathrm{mg}$

- $1000 \mathrm{mg}$

Fig. 4 Verification of the ciprofloxacin PBPK model for the investigated dose range by comparing simulation/observation ratios of mean AUC following $\mathbf{a}$ intravenous and $\mathbf{b}$ oral administration, or $C_{\max }$ following $\mathbf{c}$ oral administration of ciprofloxacin from various clinical studies in healthy adults at the indicated doses. The thick black line represents the line of identity (simulated/observed ratio $=1$ ), the grey shaded area represents the 1.25 -fold window, and the dashed lines indicate the twofold range. $P B P K$ physiologically-based pharmacokinetic, $A U C$ area under the plasma concentration-time curve, $C_{\max }$ maximum plasma concentration
Fig. 5 Predictive performance of the PBPK model indicated by predictive versus observed mean (filled symbols) plasma concentration data of pediatric (diamonds) [55, 56] and geriatric (squares) patients $[6,25,46,47,50,76]$ following intravenous (left) and oral (right) administration. The thick black line represents the line of identity, and the dashed lines indicate the twofold range. $P B P K$ physiologically-based pharmacokinetic
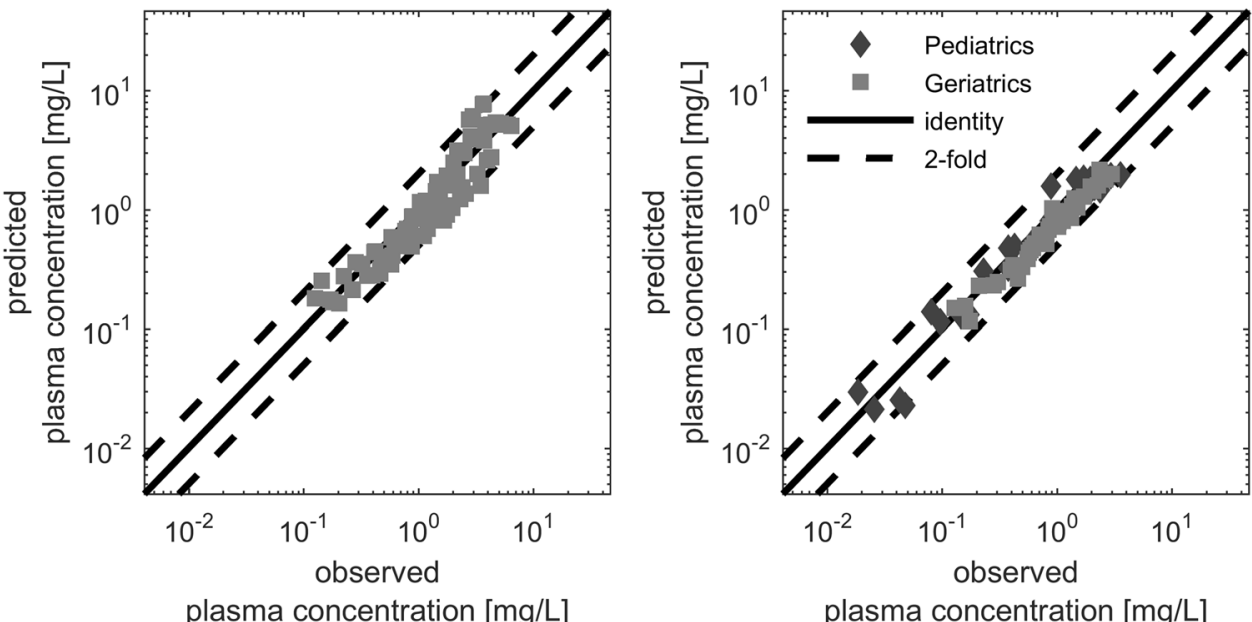

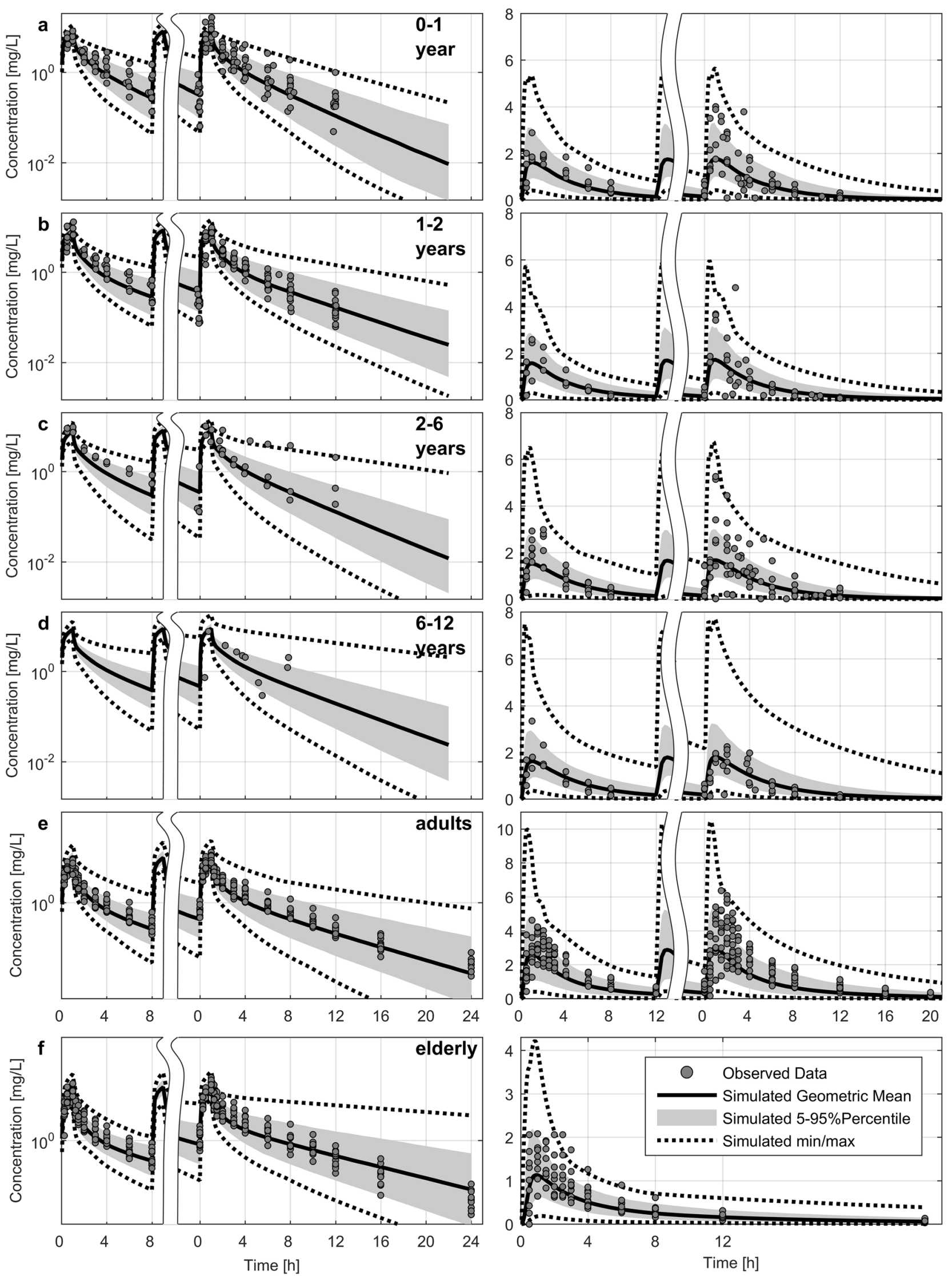
tant with increasing age. Generally, most parameters showed a similar impact of age, while only dose had the same sensitivity for all age groups.

\section{Discussion}

Over the past decade, PBPK modeling and simulation in special population groups gained more attention, but confidence in this methodology still needs to flourish with continuous improvement and qualification due to the complexity of system-related parameter information. Regulators consider PBPK modeling as a promising approach to inform dosing regimens for pediatric pharmacotherapy [104]; designated guidelines for conducting and reporting of PBPK analyses have recently been published [105, 106]. In addition to the increased popularity of pediatric PBPK modeling to assess pharmacokinetics and pharmacodynamics, recent efforts to extend scientifically sound system information to the other end of the age scale [96] account for an obvious need [107, 108].

In this study, the first lifespan pharmacokinetic predictions for ciprofloxacin based on a PBPK model were
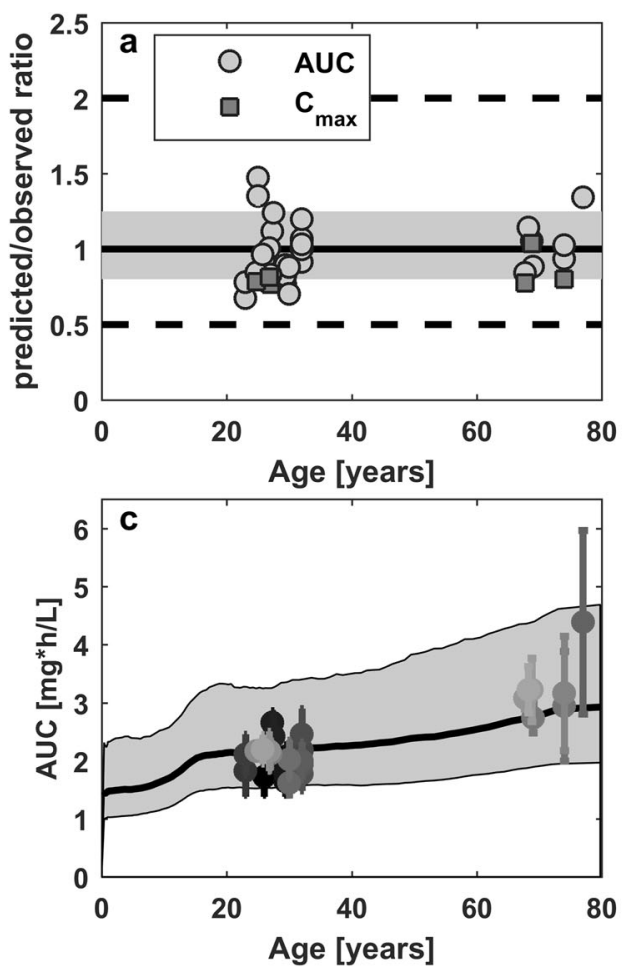

Fig. 7 Model predictions for the AUC and $C_{\max }$ following intravenous (left) and oral (right) administration. Observed values reported in Tables 1 and 2 versus predicted values over age are shown in the upper panel for both parameters. In this figure, the solid line represents the line of unity, the grey shaded area represents the 1.25fold level, and the dashed black lines represent the twofold level of the predicted accuracy. The AUC after intravenous (c) and $C_{\max }$ after
Fig. 8 Listing of the most sensitive parameters towards $\mathrm{AUC}_{\infty}$ (above the $90 \%$ cut-off; middle panel) and $C_{\max }$ (bottom panel) after oral administration, and the $\mathrm{AUC}_{\infty}$ after intravenous administration (top panel), in descending order. The $x$-axis describes sensitivity values and their positive or negative impact on $\mathrm{AUC}_{\infty}$. Color coding indicates the different ages. $A U C_{\infty}$ area under the concentration-time curve from time zero to infinity, $C_{\max }$ maximum plasma concentration

successfully performed using comprehensive physiological information. In addition, a model assessment for predictions based on a large-scale SA was introduced and performed.

After the development of a ciprofloxacin adult PBPK model for intravenous administration based on in vitro and adult pharmacokinetic data, the model was verified for extended simulations in a subsequent step. Visual prediction checks for mean plasma concentration-time data revealed a successful description of the observed data. The assessment of estimated pharmacokinetic parameters leads to an equally well-described description of the investigated dose range, verifying the distribution-, metabolism- and elimination-related parameterization. This also confirmed the underlying dose linearity of ciprofloxacin since the
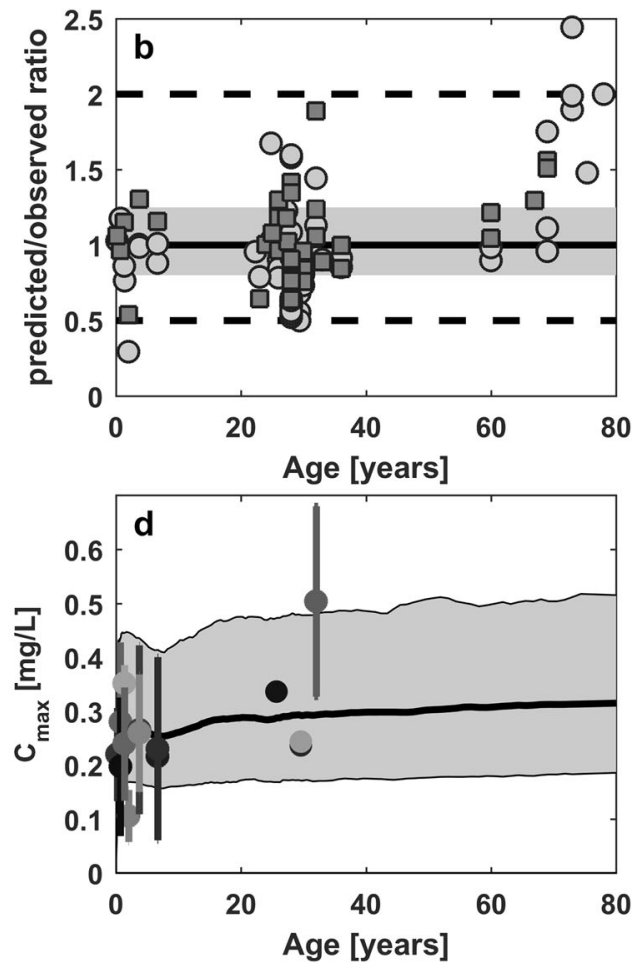

oral (d) suspension dosing prediction over age for a dose of $1 \mathrm{mg} / \mathrm{kg}$ are visualized in the lower panel. In this figure, predicted population data were represented as the geometric mean (thick black line) and 90\% prediction interval (grey shaded area). Observed, dose-normalized pharmacokinetic measures indicate reported means (dots) and standard deviations (error bars). $A U C$ area under the plasma concentration-time curve, $C_{\max }$ maximum plasma concentration 
Dose

Fraction unbound

Plasma protein scale factor

Kidney Volume

Hematocrit

Tubular Secretion Clearance

Liver Volume

Kidney Volume

Kidney specific blood flow rate

Biliary Clearance (Reference Body Weight)

Biliary Clearance

Biliary Clearance (Reference Fraction Unbound)

Biliary Clearance (Reference Fraction Intracellular)

Biliary Clearance (Reference Liver Volume)

CYP1A2 (Reference Fraction Intracellular)

CYP1A2 (Reference Liver Volume)

CYP1A2-Reference concentration

CYP1A2 Intrinsic Clearance

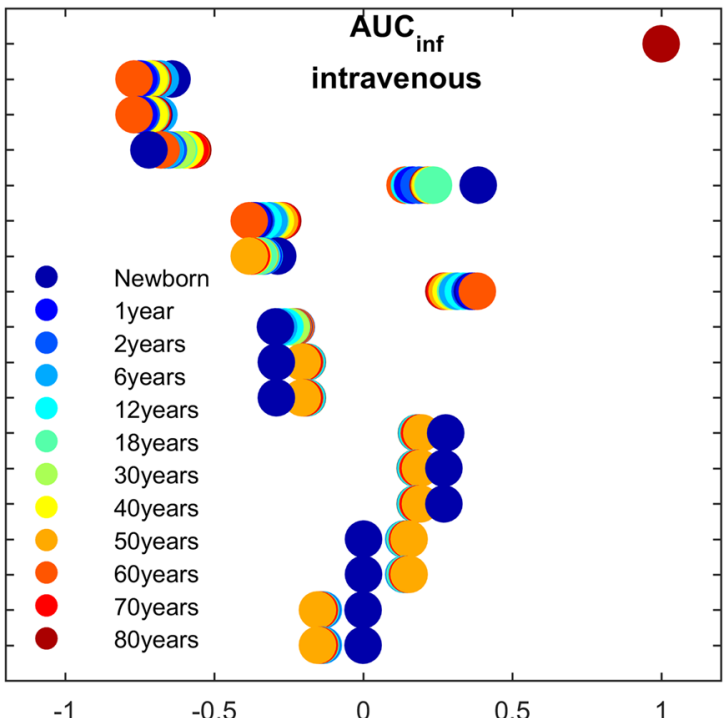

Dose

Fraction unbound

Plasma protein scale factor

Kidney Volume

Liver Volume

Biliary Clearance (Reference Body Weight)

Biliary Clearance

Biliary Clearance (Reference Fraction Unbound)

Biliary Clearance (Reference Fraction Intracellular)

Biliary Clearance (Reference Liver Volume)

Tubular Secretion Clearance

Kidney Volume

Hematocrit

Kidney specific blood flow rate

CYP1A2 (Reference Fraction Intracellular)

CYP1A2 (Reference Liver Volume)

CYP1A2-Reference concentration

CYP1A2 Intrinsic Clearance

CYP1A2 (Hepatic relative expression) Lipophilicity

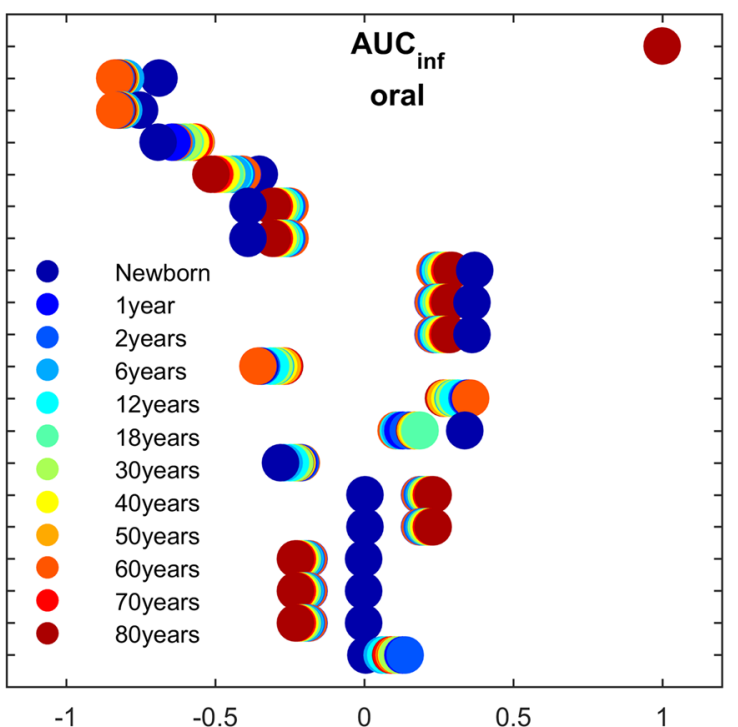

Dose

Fraction unbound

Plasma protein scale factor

Dissolution time ( $50 \%$ dissolved)

Lipophilicity

Kidney Volume

Liver Volume

Fat Volume

Biliary Clearance (Reference Body Weight) Biliary Clearance

Biliary Clearance (Reference Fraction Unbound)

Biliary Clearance (Reference Fraction Intracellular)

Biliary Clearance (Reference Liver Volume) Muscle Volume Hematocrit

Fat-Specific blood flow rate

Tubular Secretion Clearance

$$
\text { Kidney Volume }
$$

Kidney specific blood flow rate

CYP1A2 (Reference Fraction Intracellular)

CYP1A2 (Reference Liver Volume)

CYP1A2 Intrinsic Clearance

CYP1A2-Reference concentration

CYP1A2 (Hepatic relative expression)

Bone Volume

Dissolution shape

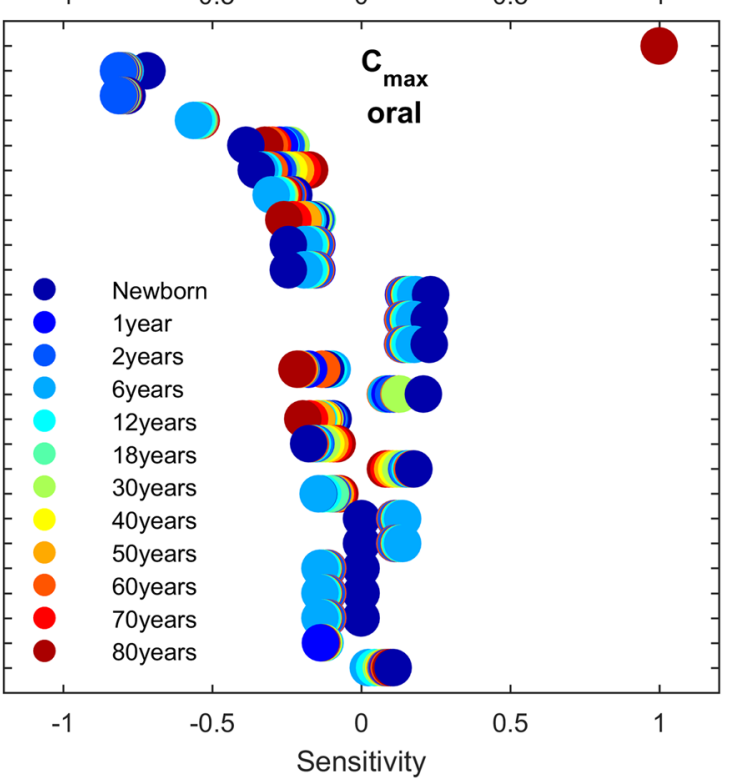


PBPK model was built solely with linear elimination processes.

The model application for exposure simulation following intravenous administration for adults was then adjusted in relation to gastrointestinal absorption following oral administration. Similar to a recent study by Martinez et al., $A_{\text {eff }}$ Factors were estimated to describe the transporter-mediated impact of segmental absorption [109]. Generally, the model-based net absorption needed to increase in all segments, showing a large uptake in the duodenum and jejunum. This is in line with previous observations following administration of a remote-control capsule [110]. A saturated absorption with increasing doses, as discussed previously, was not observed in the estimation steps [63], which might be due to the administration of multiple tablets to achieve higher dose levels, thereby causing limitations in tablet dissolution rather than in absorption. For the mean plasma concentration-time data, only $4.82 \%$ of the simulation-to-observation ratios after intravenous administration, and $12.13 \%$ after oral administration, were outside the twofold change range (Figs. 2, 3). The resulting simulation-to-observation ratio values for $\mathrm{AUC}$ and $C_{\max }$ were evenly distributed across the line of identity.

Subsequent scaling to both ends of the age scale revealed a robust estimation of age-related exposure changes. Trends in AUC changes reported in the literature were adequately predicted for intravenous and oral dosing. Prediction-to-observation ratios revealed similar accuracy for the mean plasma concentration-time data compared with adults. The increasing variability in $C_{\max }$ towards younger age groups was captured by the model predictions. Since small intestinal transit time has a notable impact on $C_{\max }$ based on the $\mathrm{SA}$, but was shown to be barely agedependent [111], an even higher net absorption for some individuals in the duodenum or jejunum might explain the scattered instances of elevated maximum plasma exposure. Although pharmacokinetic observations of ciprofloxacin in neonates have been published, these data were not considered in this analysis since neonates in those studies were pooled with other pediatric age groups [12] or were treated with varying dosing schemes [112, 113].

In the present study, PI was applied to simultaneously identify lipophilicity and initial elimination parameterization for intravenous administration, as well as to inform in vivo dissolution profiles and the segmental absorption pattern. The influence of these initially uncertain parameters was later assessed in an SA. Use of the SA helps to identify model uncertainties and foster communication between the model developer and the clinical pharmacologist, who gains a better understanding of the applicability of a model in a clinical setting. The SA was conducted to scrutinize how age-dependent changes affect systemic exposure, and to assess the impact of identified parameters on model performance. In the main, parameters related to the kinetics of metabolism and excretion were found to be crucial for the simulated pharmacokinetics (Fig. 8); however, the metabolism and excretion kinetic rates for each pathway were informed by previously reported mass-balance studies that support confidence in the identified rates [8].

Over recent years, several PBPK models for ciprofloxacin have been published with different grades of complexity, depending on the purpose of the respective studies. First, the authors of this study published a wholebody PBPK approach to exemplify best practice in the model-building procedure by following simple model learning steps, which allowed already reasonable pharmacokinetic approximations but lacked generality [15]. Later, Sadiq et al. parameterized an ordinary differential equation system in NONMEM based on plasma observations in intensive care patients in order to predict target tissue concentrations and the time-course of bacterial killing at different sites of infection [114]. Ball et al. and Navid et al. evaluated drug-drug interaction (DDI) potential using ciprofloxacin as a perpetrator drug for renal transporters [59] and CYP1A2 [115]. In the latter case model, verification was not described, while the only verification dataset used in the Ball et al. study was underpredicted after single-dose administration. Furthermore, only Ball et al. developed a full PBPK model on a commercial PBPK platform, which potentially allows for age-dependent absorption, distribution, metabolism, and excretion (ADME) scaling using the underlying databases on physiology and ontogeny. Navid et al. conducted DDI predictions in the elderly by adjusting the unspecific clearance, without taking into account general physiological changes in older adults.

A mechanistic description of the oral absorption of ciprofloxacin has been covered by two publications. First, Martinez et al. investigated the peculiarities of the oral absorption of ciprofloxacin with dedicated clinical trials and sophisticated stepwise information of model processes [109], while Hansmann et al. recently focused on the dosage form dissolution mechanisms and tried to inform in vivo behavior with in vitro dissolution, transfer and twostage experiments [116]. Both approaches were conducted using a commercial platform, but described systemic exposure with a (non)compartmental approach. Unevaluated model predictions by Hansmann et al. towards the older age range showed a lower $C_{\max }$ than in adults, which is contrary to published clinical observations [50] and the predictions presented in this study. All these PBPK models allocate between renal and non-renal clearance without precise distinctions of separate processes. This limits the potential pharmacokinetic evaluation of the age- or disease-related impact on these specific processes, which is 
explicitly considered and informed in the hereby presented PBPK model.

\section{Conclusions}

This developed and verified ciprofloxacin lifespan PBPK model comprises a thoroughly informed basis for mechanistic representation of the compound's ADME processes, which allows reliable scaling to both ends of the age scale. Therefore, such a model can be used to support clinical trial designs or optimize dose regimens. Special pharmacokinetic-related questions triggered by certain clinical scenarios can be responded to adequately for this multipathway drug over the entire age span. Further pharmacokinetic assessments in other special population groups, or an evaluation of biopharmaceutical issues during formulation development, are potential application scenarios and support subsequent pharmacodynamic model extension. This work also demonstrates the importance of an adequately established and verified PBPK model incorporating profound prior knowledge to allow a scientifically sound prediction.

\section{Compliance with Ethical Standards}

Funding This work was funded by Bayer AG. No additional funds were used in the preparation of this manuscript.

Conflicts of interest Jan-Frederik Schlender is a $\mathrm{PhD}$ student at the University of Bonn, and was employed on a Grant from Bayer Technology Services GmbH (now Bayer AG) during the preparation of this manuscript. Jan-Frederik Schlender, Katrin Coeboeken, Katrin Schnizler, Thomas Eissing, Stefan Willmann and Heino Stass are employed by Bayer AG and are potential stock holders of Bayer AG. Donato Teutonico was employed by Bayer AG during the preparation of this manuscript. Ulrich Jaehde has received a research Grant from Bayer Technology Services GmbH (between 2013 and 2015).

Open Access This article is distributed under the terms of the Creative Commons Attribution-NonCommercial 4.0 International License (http://creativecommons.org/licenses/by-nc/4.0/), which permits any noncommercial use, distribution, and reproduction in any medium, provided you give appropriate credit to the original author(s) and the source, provide a link to the Creative Commons license, and indicate if changes were made.

\section{References}

1. Neuhauser MM, Weinstein RA, Rydman R, Danziger LH, Karam G, Quinn JP. Antibiotic resistance among gram-negative bacilli in US intensive care units: implications for fluoroquinolone use. JAMA. 2003;289:885-8.

2. Hoffler D, Dalhoff A, Gau W, Beermann D, Michl A. Dose- and sex-independent disposition of ciprofloxacin. Eur J Clin Microbiol. 1984;3:363-6.
3. Olivera ME, Manzo RH, Junginger HE, Midha KK, Shah VP, Stavchansky S, et al. Biowaiver monographs for immediate release solid oral dosage forms: ciprofloxacin hydrochloride. J Pharm Sci. 2011;100:22-33.

4. Wu CY, Benet LZ. Predicting drug disposition via application of BCS: transport/absorption/elimination interplay and development of a biopharmaceutics drug disposition classification system. Pharm Res. 2005;22:11-23.

5. Honeybourne D, Wise R, Andrews JM. Ciprofloxacin penetration into lungs. Lancet. 1987;1:1040.

6. Naber KG, Sorgel F, Kees F, Jaehde U, Schumacher H. Pharmacokinetics of ciprofloxacin in young (healthy volunteers) and elderly patients, and concentrations in prostatic fluid, seminal fluid, and prostatic adenoma tissue following intravenous administration. Am J Med. 1989;87:57S-9S.

7. Wolff M, Boutron L, Singlas E, Clair B, Decazes JM, Regnier B. Penetration of ciprofloxacin into cerebrospinal fluid of patients with bacterial meningitis. Antimicrob Agents Chemother. 1987;31:899-902.

8. Rohwedder RW, Bergan T, Thorsteinsson SB, Scholl H. Transintestinal elimination of ciprofloxacin. Diagn Microbiol Infect Dis. 1990;13:127-33.

9. Jaehde U, Sorgel F, Reiter A, Sigl G, Naber KG, Schunack W. Effect of probenecid on the distribution and elimination of ciprofloxacin in humans. Clin Pharmacol Ther. 1995;58:532-41.

10. Bergan T, Dalhoff A, Rohwedder R. Pharmacokinetics of ciprofloxacin. Infection. 1988;16(Suppl 1):S3-13.

11. Sorgel F, Naber KG, Jaehde U, Reiter A, Seelmann R, Sigl G. Gastrointestinal secretion of ciprofloxacin. Evaluation of the charcoal model for investigations in healthy volunteers. Am J Med. 1989;87:62S-5S.

12. Payen S, Serreau R, Munck A, Aujard Y, Aigrain Y, Bressolle F, et al. Population pharmacokinetics of ciprofloxacin in pediatric and adolescent patients with acute infections. Antimicrob Agents Chemother. 2003;47:3170-8.

13. Rajagopalan P, Gastonguay MR. Population pharmacokinetics of ciprofloxacin in pediatric patients. J Clin Pharmacol. 2003;43:698-710.

14. Forrest A, Ballow CH, Nix DE, Birmingham MC, Schentag JJ. Development of a population pharmacokinetic model and optimal sampling strategies for intravenous ciprofloxacin. Antimicrob Agents Chemother. 1993;37:1065-72.

15. Kuepfer L, Niederalt C, Wendl T, Schlender JF, Willmann S, Lippert J, et al. Applied concepts in PBPK modeling: how to Build a PBPK/PD Model. CPT Pharmacometrics Syst Pharmacol. 2016;5:516-31.

16. Yoshida K, Budha N, Jin JY. Impact of physiologically based pharmacokinetic models on regulatory reviews and product labels: frequent utilization in the field of oncology. Clin Pharmacol Ther. 2017;101:597-602.

17. van Zanten AR, Polderman KH, van Geijlswijk IM, van der Meer GY, Schouten MA, Girbes AR. Ciprofloxacin pharmacokinetics in critically ill patients: a prospective cohort study. J Crit Care. 2008;23:422-30.

18. Lipman J, Scribante J, Gous AG, Hon H, Tshukutsoane S. Pharmacokinetic profiles of high-dose intravenous ciprofloxacin in severe sepsis. The Baragwanath Ciprofloxacin Study Group. Antimicrob Agents Chemother. 1998;42:2235-9.

19. Ruhnke M, Trautmann M, Borner K, Hopfenmuller W. Pharmacokinetics of ciprofloxacin in liver cirrhosis. Chemotherapy. 1990;36:385-91.

20. Frost RW, Lettieri JT, Krol G, Shamblen EC, Lasseter KC. The effect of cirrhosis on the steady-state pharmacokinetics of oral ciprofloxacin. Clin Pharmacol Ther. 1989;45:608-16. 
21. Hackam DJ, Christou N, Khaliq Y, Duffy DR, Vaughan D, Marshall JC, et al. Bioavailability of oral ciprofloxacin in early postsurgical patients. Arch Surg. 1998;133:1221-5.

22. Cohn SM, Cohn KA, Rafferty MJ, Smith AH, Degutis LC, Kowalsky SF, et al. Enteric absorption of ciprofloxacin during the immediate postoperative period. J Antimicrob Chemother. 1995;36:717-21.

23. Gattis WA, Petros WP, Pickard WW, Drew RH, May DB, Hathorn JW. A prospective, open-label study of single-dose ciprofloxacin absorption after chemotherapy in patients with malignancy. Pharmacotherapy. 1997;17:836-40.

24. Johnson EJ, MacGowan AP, Potter MN, Stockley RJ, White LO, Slade RR, et al. Reduced absorption of oral ciprofloxacin after chemotherapy for haematological malignancy. J Antimicrob Chemother. 1990;25:837-42.

25. Shah A, Lettieri J, Nix D, Wilton J, Heller AH. Pharmacokinetics of high-dose intravenous ciprofloxacin in young and elderly and in male and female subjects. Antimicrob Agents Chemother. 1995;39:1003-6.

26. Bayer A, Gajewska A, Stephens M, Stark JM, Pathy J. Pharmacokinetics of ciprofloxacin in the elderly. Respiration. 1987;51:292-5.

27. Israel D, Gillum JG, Turik M, Harvey K, Ford J, Dalton H, et al. Pharmacokinetics and serum bactericidal titers of ciprofloxacin and ofloxacin following multiple oral doses in healthy volunteers. Antimicrob Agents Chemother. 1993;37:2193-9.

28. Wacha H, Wagner D, Schafer V, Knothe H. Concentration of ciprofloxacin in bone tissue after single parenteral administration to patients older than 70 years. Infection. 1990;18:173-6.

29. Gonzalez MA, Moranchel AH, Duran S, Pichardo A, Magana $\mathrm{JL}$, Painter B, et al. Multiple-dose ciprofloxacin dose ranging and kinetics. Clin Pharmacol Ther. 1985;37:633-7.

30. Ljungberg B, Nilsson-Ehle I. Pharmacokinetics of intravenous ciprofloxacin at three different doses. J Antimicrob Chemother. 1988;22:715-20.

31. Borner K, Hoffken G, Lode H, Koeppe P, Prinzing C, Glatzel P, et al. Pharmacokinetics of ciprofloxacin in healthy volunteers after oral and intravenous administration. Eur J Clin Microbiol. 1986;5:179-86.

32. Hoffken G, Lode H, Prinzing C, Borner K, Koeppe P. Pharmacokinetics of ciprofloxacin after oral and parenteral administration. Antimicrob Agents Chemother. 1985;27:375-9.

33. Dudley MN, Ericson J, Zinner SH. Effect of dose on serum pharmacokinetics of intravenous ciprofloxacin with identification and characterization of extravascular compartments using noncompartmental and compartmental pharmacokinetic models. Antimicrob Agents Chemother. 1987;31:1782-6.

34. Bergan T, Thorsteinsson SB, Kolstad IM, Johnsen S. Pharmacokinetics of ciprofloxacin after intravenous and increasing oral doses. Eur J Clin Microbiol. 1986;5:187-92.

35. Bergan T, Thorsteinsson SB, Solberg R, Bjornskau L, Kolstad IM, Johnsen S. Pharmacokinetics of ciprofloxacin: intravenous and increasing oral doses. Am J Med. 1987;82:97-102.

36. Wingender W, Graefe KH, Gau W, Forster D, Beermann D, Schacht P. Pharmacokinetics of ciprofloxacin after oral and intravenous administration in healthy volunteers. Eur J Clin Microbiol. 1984;3:355-9.

37. Wise R, Lockley RM, Webberly M, Dent J. Pharmacokinetics of intravenously administered ciprofloxacin. Antimicrob Agents Chemother. 1984;26:208-10.

38. Drusano GL, Plaisance KI, Forrest A, Standiford HC. Dose ranging study and constant infusion evaluation of ciprofloxacin. Antimicrob Agents Chemother. 1986;30:440-3.

39. Gonzalez MA, Moranchel AH, Duran S, Pichardo A, Magana JL, Painter B, et al. Multiple-dose pharmacokinetics of ciprofloxacin administered intravenously to normal volunteers. Antimicrob Agents Chemother. 1985;28:235-9.

40. Nix DE, Spivey JM, Norman A, Schentag JJ. Dose-ranging pharmacokinetic study of ciprofloxacin after 200-, 300-, and 400-mg intravenous doses. Ann Pharmacother. 1992;26:8-10.

41. Garraffo R, Drugeon HB. Comparative assessment of the pharmacokinetics and pharmacodynamics of ciprofloxacin after single i.v. doses of 200 and $400 \mathrm{mg}$. Drugs. 1995;49(Suppl 2):317-20.

42. Plaisance KI, Drusano GL, Forrest A, Bustamante CI, Standiford HC. Effect of dose size on bioavailability of ciprofloxacin. Antimicrob Agents Chemother. 1987;31:956-8.

43. Drusano GL, Weir M, Forrest A, Plaisance K, Emm T, Standiford HC. Pharmacokinetics of intravenously administered ciprofloxacin in patients with various degrees of renal function. Antimicrob Agents Chemother. 1987;31:860-4.

44. Pea F, Milaneschi R, Baraldo M, Lugatti E, Talmassons G, Furlanut M. Ciprofloxacin disposition in elderly patients with LRTI being treated with sequential therapy (200 mg intravenously twice daily followed by $500 \mathrm{mg}$ per os twice daily): comparative pharmacokinetics and the role of therapeutic drug monitoring. Ther Drug Monit. 2000;22:386-91.

45. Cios A, Wyska E, Szymura-Oleksiak J, Grodzicki T. Population pharmacokinetic analysis of ciprofloxacin in the elderly patients with lower respiratory tract infections. Exp Gerontol. 2014;57:107-13.

46. Kees F, Naber KG, Meyer GP, Grobecker H. Pharmacokinetics of ciprofloxacin in elderly patients. Arzneimittelforschung. 1989;39:523-7.

47. Hirata CA, Guay DR, Awni WM, Stein DJ, Peterson PK. Steady-state pharmacokinetics of intravenous and oral ciprofloxacin in elderly patients. Antimicrob Agents Chemother. 1989;33:1927-31.

48. Davis RL, Koup JR, Williams-Warren J, Weber A, Heggen L, Stempel D, et al. Pharmacokinetics of ciprofloxacin in cystic fibrosis. Antimicrob Agents Chemother. 1987;31:915-9.

49. Drusano GL, Standiford HC, Plaisance K, Forrest A, Leslie J, Caldwell J. Absolute oral bioavailability of ciprofloxacin. Antimicrob Agents Chemother. 1986;30:444-6.

50. Ljungberg B, Nilsson-Ehle I. Pharmacokinetics of ciprofloxacin in the elderly: increased oral bioavailability and reduced renal clearance. Eur J Clin Microbiol Infect Dis. 1989;8:515-20.

51. Lettieri JT, Rogge MC, Kaiser L, Echols RM, Heller AH. Pharmacokinetic profiles of ciprofloxacin after single intravenous and oral doses. Antimicrob Agents Chemother. 1992;36:993-6.

52. Catchpole C, Andrews JM, Woodcock J, Wise R. The comparative pharmacokinetics and tissue penetration of single-dose ciprofloxacin $400 \mathrm{mg}$ i.v. and $750 \mathrm{mg}$ po. J Antimicrob Chemother. 1994;33:103-10.

53. Shah A, Lettieri J, Kaiser L, Echols R, Heller AH. Comparative pharmacokinetics and safety of ciprofloxacin $400 \mathrm{mg}$ i.v. thrice daily versus $750 \mathrm{mg}$ po twice daily. J Antimicrob Chemother. 1994;33:795-801.

54. Salam MA, Dhar U, Khan WA, Bennish ML. Randomised comparison of ciprofloxacin suspension and pivmecillinam for childhood shigellosis. Lancet. 1998;352:522-7.

55. Peltola H, Ukkonen P, Saxen H, Stass H. Single-dose and steady-state pharmacokinetics of a new oral suspension of ciprofloxacin in children. Pediatrics. 1998;101:658-62.

56. Peltola H, Vaarala M, Renkonen OV, Neuvonen PJ. Pharmacokinetics of single-dose oral ciprofloxacin in infants and small children. Antimicrob Agents Chemother. 1992;36:1086-90.

57. Shah A, Liu MC, Vaughan D, Heller AH. Oral bioequivalence of three ciprofloxacin formulations following single-dose administration: $500 \mathrm{mg}$ tablet compared with $500 \mathrm{mg} / 10 \mathrm{~mL}$ or $500 \mathrm{mg} / 5 \mathrm{~mL}$ suspension and the effect of food on the absorption of ciprofloxacin oral suspension. J Antimicrob Chemother. 1999;43 Suppl A:49-54. 
58. Davis RL, Koup JR, Williams-Warren J, Weber A, Smith AL. Pharmacokinetics of three oral formulations of ciprofloxacin. Antimicrob Agents Chemother. 1985;28:74-7.

59. Ball K, Jamier T, Parmentier Y, Denizot C, Mallier A, Chenel M. Prediction of renal transporter-mediated drug-drug interactions for a drug which is an OAT substrate and inhibitor using PBPK modelling. Eur J Pharm Sci. 2017;106:122-32.

60. Gonzalez MA, Uribe F, Moisen SD, Fuster AP, Selen A, Welling PG, et al. Multiple-dose pharmacokinetics and safety of ciprofloxacin in normal volunteers. Antimicrob Agents Chemother. 1984;26:741-4.

61. Ledergerber B, Bettex JD, Joos B, Flepp M, Luthy R. Effect of standard breakfast on drug absorption and multiple-dose pharmacokinetics of ciprofloxacin. Antimicrob Agents Chemother. 1985;27:350-2.

62. Aronoff GE, Kenner CH, Sloan RS, Pottratz ST. Multiple-dose ciprofloxacin kinetics in normal subjects. Clin Pharmacol Ther. 1984;36:384-8.

63. Tartaglione TA, Raffalovich AC, Poynor WJ, Espinel-Ingroff A, Kerkering TM. Pharmacokinetics and tolerance of ciprofloxacin after sequential increasing oral doses. Antimicrob Agents Chemother. 1986;29:62-6.

64. LeBel M, Bergeron MG, Vallee F, Fiset C, Chasse G, Bigonesse $\mathrm{P}$, et al. Pharmacokinetics and pharmacodynamics of ciprofloxacin in cystic fibrosis patients. Antimicrob Agents Chemother. 1986;30:260-6.

65. Brumfitt W, Franklin I, Grady D, Hamilton-Miller JM, Iliffe A. Changes in the pharmacokinetics of ciprofloxacin and fecal flora during administration of a 7-day course to human volunteers. Antimicrob Agents Chemother. 1984;26:757-61.

66. Loi CM, Parker BM, Cusack BJ, Vestal RE. Aging and drug interactions. III. Individual and combined effects of cimetidine and cimetidine and ciprofloxacin on theophylline metabolism in healthy male and female nonsmokers. J Pharmacol Exp Ther. 1997;280:627-37.

67. Bergan T, Delin C, Johansen S, Kolstad IM, Nord CE, Thorsteinsson SB. Pharmacokinetics of ciprofloxacin and effect of repeated dosage on salivary and fecal microflora. Antimicrob Agents Chemother. 1986;29:298-302.

68. Wagenlehner FM, Wydra S, Onda H, Kinzig-Schippers M, Sorgel F, Naber KG. Concentrations in plasma, urinary excretion, and bactericidal activity of linezolid (600 milligrams) versus those of ciprofloxacin (500 milligrams) in healthy volunteers receiving a single oral dose. Antimicrob Agents Chemother. 2003;47:3789-94.

69. Kara M, Hasinoff BB, McKay DW, Campbell NR. Clinical and chemical interactions between iron preparations and ciprofloxacin. Br J Clin Pharmacol. 1991;31:257-61.

70. Crump B, Wise R, Dent J. Pharmacokinetics and tissue penetration of ciprofloxacin. Antimicrob Agents Chemother. 1983;24:784-6.

71. Boy D, Well M, Kinzig-Schippers M, Sorgel F, Ankel-Fuchs D, Naber KG. Urinary bactericidal activity, urinary excretion and plasma concentrations of gatifloxacin $(400 \mathrm{mg})$ versus ciprofloxacin $(500 \mathrm{mg})$ in healthy volunteers after a single oral dose. Int J Antimicrob Agents. 2004;23(Suppl 1):S6-16.

72. Gotfried MH, Danziger LH, Rodvold KA. Steady-state plasma and intrapulmonary concentrations of levofloxacin and ciprofloxacin in healthy adult subjects. Chest. 2001;119:1114-22.

73. Esposito S, Miniero M, Barba D, Sagnelli E. Pharmacokinetics of ciprofloxacin in impaired liver function. Int J Clin Pharmacol Res. 1989;9:37-41.

74. Gasser TC, Ebert SC, Graversen PH, Madsen PO. Ciprofloxacin pharmacokinetics in patients with normal and impaired renal function. Antimicrob Agents Chemother. 1987;31:709-12.
75. Boerema JB, Dalhoff A, Debruyne FM. Ciprofloxacin distribution in prostatic tissue and fluid following oral administration. Chemotherapy. 1985;31:13-8.

76. LeBel M, Barbeau G, Bergeron MG, Roy D, Vallee F. Pharmacokinetics of ciprofloxacin in elderly subjects. Pharmacotherapy. 1986;6:87-91.

77. Frost RW, Carlson JD, Dietz AJ Jr, Heyd A, Lettieri JT. Ciprofloxacin pharmacokinetics after a standard or high-fat/ high-calcium breakfast. J Clin Pharmacol. 1989;29:953-5.

78. Overholser BR, Kays MB, Forrest A, Sowinski KM. Sex-related differences in the pharmacokinetics of oral ciprofloxacin. J Clin Pharmacol. 2004;44:1012-22.

79. Gallicano K, Sahai J. Lack of gender effect on ciprofloxacin pharmacokinetics in humans. $\mathrm{Br} \mathrm{J}$ Clin Pharmacol. 1996;42:632-4.

80. Dan M, Verbin N, Gorea A, Nagar H, Berger SA. Concentrations of ciprofloxacin in human liver, gallbladder, and bile after oral administration. Eur J Clin Pharmacol. 1987;32:217-8.

81. Dan M, Zuabi T, Quassem C, Rotmensch HH. Distribution of ciprofloxacin in ascitic fluid following administration of a single oral dose of 750 milligrams. Antimicrob Agents Chemother. 1992;36:677-8.

82. Weinstein MP, Deeter RG, Swanson KA, Gross JS. Crossover assessment of serum bactericidal activity and pharmacokinetics of ciprofloxacin alone and in combination in healthy elderly volunteers. Antimicrob Agents Chemother. 1991;35:2352-8.

83. Yuk JH, Nightingale CN, Quintiliani R. Ciprofloxacin levels when receiving sucralfate. JAMA. 1989;262:901.

84. Dan M, Golomb J, Gorea A, Braf Z, Berger SA. Concentration of ciprofloxacin in human prostatic tissue after oral administration. Antimicrob Agents Chemother. 1986;30:88-9.

85. Chandler MH, Toler SM, Rapp RP, Muder RR, Korvick JA. Multiple-dose pharmacokinetics of concurrent oral ciprofloxacin and rifampin therapy in elderly patients. Antimicrob Agents Chemother. 1990;34:442-7.

86. Guay DR, Awni WM, Peterson PK, Obaid S, Stein D, Breitenbucher R, et al. Single and multiple dose pharmacokinetics of oral ciprofloxacin in elderly patients. Int J Clin Pharmacol Ther Toxicol. 1988;26:279-84.

87. Lubart E, Berkovitch M, Leibovitz A, Britzi M, Soback S, Bukasov Y, et al. Pharmacokinetics of ciprofloxacin in hospitalized geriatric patients: comparison between nasogastric tube and oral administration. Ther Drug Monit. 2013;35:653-6.

88. Aggarwal P, Dutta S, Garg SK, Narang A. Multiple dose pharmacokinetics of ciprofloxacin in preterm babies. Indian Pediatr. 2004;41:1001-7.

89. Alvarez AI, Perez M, Prieto JG, Molina AJ, Real R, Merino G. Fluoroquinolone efflux mediated by ABC transporters. J Pharm Sci. 2008;97:3483-93.

90. Vanwert AL, Srimaroeng C, Sweet DH. Organic anion transporter 3 (oat3/slc22a8) interacts with carboxyfluoroquinolones, and deletion increases systemic exposure to ciprofloxacin. Mol Pharmacol. 2008;74:122-31.

91. Granfors MT, Backman JT, Neuvonen M, Neuvonen PJ. Ciprofloxacin greatly increases concentrations and hypotensive effect of tizanidine by inhibiting its cytochrome P450 1A2mediated presystemic metabolism. Clin Pharmacol Ther. 2004;76:598-606.

92. Parry MF, Smego DA, Digiovanni MA. Hepatobiliary kinetics and excretion of ciprofloxacin. Antimicrob Agents Chemother. 1988;32:982-5.

93. Thelen K, Coboeken K, Willmann S, Burghaus R, Dressman JB, Lippert J. Evolution of a detailed physiological model to simulate the gastrointestinal transit and absorption process in humans, part 1: oral solutions. J Pharm Sci. 2011;100:5324-45. 
94. Edginton AN, Schmitt W, Voith B, Willmann S. A mechanistic approach for the scaling of clearance in children. Clin Pharmacokinet. 2006;45:683-704.

95. Edginton AN, Schmitt W, Willmann S. Development and evaluation of a generic physiologically based pharmacokinetic model for children. Clin Pharmacokinet. 2006;45:1013-34.

96. Schlender JF, Meyer M, Thelen K, Krauss M, Willmann S, Eissing T, et al. Development of a whole-body physiologically based pharmacokinetic approach to assess the pharmacokinetics of drugs in elderly individuals. Clin Pharmacokinet. 2016;55(12):1573-89.

97. Willmann S, Becker C, Burghaus R, Coboeken K, Edginton A, Lippert J, et al. Development of a paediatric population-based model of the pharmacokinetics of rivaroxaban. Clin Pharmacokinet. 2014;53:89-102.

98. US FDA. General clinical pharmacology considerations for pediatric studies for drugs and biological products-guidance for industry. US Department of Health and Human Services; 2014. https://www.fda.gov/downloads/drugs/guidances/ucm 425 885.pdf. Accessed 18 Apr 2018.

99. Barbosa J, Barrón D, Jiménez-Lozano E, Sanz-Nebot V. Comparison between capillary electrophoresis, liquid chromatography, potentiometric and spectrophotometric techniques for evaluation of $\mathrm{pK}$ a values of zwitterionic drugs in acetonitrilewater mixtures. Anal Chim Acta. 2001;437:309-21.

100. Varanda F, Pratas de Melo MJ, Caco AI, Dohrn R, Makrydaki FA, Voutsas E, et al. Solubility of antibiotics in different solvents. 1. Hydrochloride forms of tetracycline, moxifloxacin, and ciprofloxacin. Ind Eng Chem Res. 2006;45:6368-74.

101. Willmann S, Lippert J, Sevestre M, Solodenko J, Fois F, Fois F. W. S. PK-Sim: a physiologically based pharmacokinetic "wholebody' model. Biosilico. 2003;1:121-4.

102. Willmann S, Lippert J, Schmitt W. From physicochemistry to absorption and distribution: predictive mechanistic modelling and computational tools. Expert Opin Drug Metab Toxicol. 2005;1:159-68.

103. Leibovitz E, Janco J, Piglansky L, Press J, Yagupsky P, Reinhart $\mathrm{H}$, et al. Oral ciprofloxacin vs. intramuscular ceftriaxone as empiric treatment of acute invasive diarrhea in children. Pediatr Infect Dis J. 2000;19:1060-7.

104. Mehrotra N, Bhattaram A, Earp JC, Florian J, Krudys K, Lee JE, et al. Role of quantitative clinical pharmacology in pediatric approval and labeling. Drug Metab Dispos. 2016;44:924-33.

105. US FDA. Physiologically based pharmacokinetic analysesformat and content guidance for industry. US Department of Health and Human Services; 2016. https://www.fda.gov/ downloads/Drugs/GuidanceComplianceRegulatoryInformation/ Guidances/UCM531207.pdf. Accessed 18 Apr 2018.
106. European Medicines Agency. Draft guideline on the qualification and reporting of physiologically based pharmacokinetic (PBPK) modelling and simulation. European Medicines Agency; 2016. http://www.ema.europa.eu/docs/en_GB/ document_library/Scientific_guideline/2016/07/WC500211315. pdf. Accessed 18 Apr 2018.

107. Jadhav PR, Cook J, Sinha V, Zhao P, Rostami-Hodjegan A, Sahasrabudhe $V$, et al. A proposal for scientific framework enabling specific population drug dosing recommendations. J Clin Pharmacol. 2015;55:1073-8.

108. Lau S, Schlender JF, Abernethy DR, Burckart GJ, Golden A, Slattum PW, et al. Improving therapeutics to better care for older adults and the young: report from the American College of Clinical Pharmacology Workshop. J Clin Pharmacol. 2018;58:277-80.

109. Martinez M, Mistry B, Lukacova V, Polli J, Hoag S, Dowling T, et al. Use of modeling and simulation tools for understanding the impact of formulation on the absorption of a low solubility compound: ciprofloxacin. AAPS J. 2016;18:886-97.

110. Staib AH, Beermann D, Harder S, Fuhr U, Liermann D. Absorption differences of ciprofloxacin along the human gastrointestinal tract determined using a remote-control drug delivery device (HF-capsule). Am J Med. 1989;87:66S-9S.

111. Maharaj AR, Edginton AN. Examining small intestinal transit time as a function of age: is there evidence to support agedependent differences among children? Drug Metab Dispos. 2016;44:1080-9.

112. Leroux S, Turner MA, Guellec CB, Hill H, van den Anker JN, Kearns GL, et al. Pharmacokinetic studies in neonates: the utility of an opportunistic sampling design. Clin Pharmacokinet. 2015;54:1273-85.

113. Zhao W, Hill H, Le Guellec C, Neal T, Mahoney S, Paulus S, et al. Population pharmacokinetics of ciprofloxacin in neonates and young infants less than three months of age. Antimicrob Agents Chemother. 2014;58:6572-80.

114. Sadiq MW, Nielsen EI, Khachman D, Conil JM, Georges B, Houin G, et al. A whole-body physiologically based pharmacokinetic (WB-PBPK) model of ciprofloxacin: a step towards predicting bacterial killing at sites of infection. J Pharmacokinet Pharmacodyn. 2017;44:69-79.

115. Navid A, Ng DM, Wong SE, Lightstone FC. Application of a physiologically based pharmacokinetic model to study theophylline metabolism and its interactions with ciprofloxacin and caffeine. CPT Pharmacometrics Syst Pharmacol. 2016;5:74-81.

116. Hansmann S, Miyaji Y, Dressman J. An in silico approach to determine challenges in the bioavailability of ciprofloxacin, a poorly soluble weak base with borderline solubility and permeability characteristics. Eur J Pharm Biopharm. 2018;122:186-96. 